\title{
Identification of Modulated MicroRNAs Associated with Breast Cancer, Diet, and Physical Activity
}

\author{
Luca Falzone ${ }^{1, * \mathbb{C}}$, Maria Grimaldi ${ }^{1}$, Egidio Celentano ${ }^{1}$, Livia S. A. Augustin ${ }^{1}$ and \\ Massimo Libra 2,3,*(D) \\ 1 Epidemiology Unit, IRCCS Istituto Nazionale Tumori “Fondazione G. Pascale”, 80131 Naples, Italy; \\ m.grimaldi@istitutotumori.na.it (M.G.); e.celentano@istitutotumori.na.it (E.C.); \\ livia.augustin@utoronto.ca (L.S.A.A.) \\ 2 Department of Biomedical and Biotechnological Sciences, University of Catania, 95123 Catania, Italy \\ 3 Research Centre for Prevention, Diagnosis, and Treatment of Cancer, University of Catania, \\ 95123 Catania, Italy \\ * Correspondence: luca.falzone@unict.it (L.F.); mlibra@unict.it (M.L.); Tel.: +39-095-478-1278 (L.F.); \\ +39-095-478-1271 (M.L.)
}

Received: 20 July 2020; Accepted: 7 September 2020; Published: 8 September 2020

Simple Summary: Healthy diet and physical activity are able to induce beneficial molecular modifications that have been associated with a lower risk of breast cancer (BC) incidence and a better prognosis for $\mathrm{BC}$ patients. Although the beneficial effects of healthy lifestyle have been described, the beneficial epigenetic modifications induced by dietary and exercise intervention in $\mathrm{BC}$ patients have not been elucidated yet. On these bases, the aim of the present study was to computationally identify microRNAs (miRNAs) strictly associated with BC progression and with dietary and exercise interventions. Through several computational approaches, a set of miRNAs modulated by diet and exercise and useful as diagnostic and prognostic biomarkers for BC was identified. The results obtained represent the starting point for further validation analyses performed on BC patients undergoing lifestyle interventions to propose the miRNAs here identified as novel biomarkers for BC management.

\begin{abstract}
Background: Several studies have shown that healthy lifestyles prevent the risk of breast cancer (BC) and are associated with better prognosis. It was hypothesized that lifestyle strategies induce microRNA (miRNA) modulation that, in turn, may lead to important epigenetic modifications. The identification of miRNAs associated with $\mathrm{BC}$, diet, and physical activity may give further insights into the role played by lifestyle interventions and their efficacy for BC patients. To predict which miRNAs may be modulated by diet and physical activity in BC patients, the analyses of different miRNA expression datasets were performed. Methods: The GEO DataSets database was used to select miRNA expression datasets related to BC patients, dietary interventions, and physical exercise. Further bioinformatic approaches were used to establish the value of selected miRNAs in BC development and prognosis. Results: The analysis of datasets allowed the selection of modulated miRNAs associated with BC development, diet, and physical exercise. Seven miRNAs were also associated with the overall survival of BC patients. Conclusions: The identified miRNAs may play a role in the development of $\mathrm{BC}$ and may have a prognostic value in patients treated with integrative interventions including diet and physical activity. Validation of such modulated miRNAs on BC patients undergoing lifestyle strategies will be mandatory.
\end{abstract}

Keywords: microRNA; breast cancer; biomarkers; bioinformatics; prognosis; epigenetic; diet; physical activity 


\section{Introduction}

Breast cancer (BC) represents the second most diagnosed cancer worldwide and the leading cause of cancer death in women accounting, respectively, for 2,088,849 million new diagnoses and over 625,000 deaths annually [1]. Despite the advancement of anticancer surgical and pharmacological treatments, both $\mathrm{BC}$ incidence and mortality rates have remained almost unchanged during the last 40 years [2-4].

Recently, several integrative therapies have been proposed for the treatment of BC patients in order to improve the efficacy of standard anticancer approaches, reduce chemotherapy side effects, ameliorate patient quality of life, and to reduce BC mortality [5-7]. Currently adopted integrative therapies for BC patients include nutraceutical products like vitamins, flavonoids and natural extracts $[8,9]$, prebiotics and probiotics $[10,11]$, the adoption of a healthy lifestyle mainly represented by moderate or intense physical exercise [12,13], and the adherence to healthy or hypocaloric diets [5,14].

Such approaches have been adopted following the association of cancer development with the dysbiosis of human microbiota, unhealthy lifestyle habits, hypercaloric diets, hormonal imbalances, and metabolic disorders [15-19]. In this context, it was demonstrated that sedentary lifestyle and dietary carbohydrates have detrimental effects for insulinemia and glycemia responsible for chronic inflammation and, consequently, with neoplastic transformation [20]. In particular, some foods, characterized by high glycemic index (GI) and high dietary inflammatory index (DII), are known to alter cellular homeostasis, inducing the over-expression of pro-inflammatory cytokines and hormones including Insulin-like Growth Factor 1 (IGF-1) [21,22]. All these pro-inflammatory stimuli and growth factors can lead to the alteration of key cellular processes and signaling transduction pathways like MAPKs and PI3K/Akt pathways, prompting the malignant transformation of cells $[23,24]$. Beyond these molecular changes that alter cellular homeostasis, dietary and environmental factors are also able to induce epigenetic modifications including changes in microRNA (miRNA) expression or in genetic methylation status [25-28].

Studies have shown that diet and physical exercise are able to modulate both DNA methylation status and miRNA expression levels and possibly BC risk $[29,30]$. Several lines of evidence have been accumulated in recent years about the protective role of diet against various human cancers including breast cancer. The "Prevención con Dieta Mediterránea" (PREDIMED) study demonstrated that adherence to the Mediterranean diet and olive oil intake is associated with a significant lower risk $(68 \%)$ of BC incidence [31]. Other diets such as Okinawan and plant-based diets, low energy density, and low glycemic load dietary patterns are associated with BC prevention and better prognosis [32]. In the same manner, different studies have highlighted the protective role of exercise, which is able to reduce $B C$ incidence and mortality inducing both genetic and epigenetic modulation [33-35].

All this evidence leads researchers to investigate the epigenetic modifications and beneficial effects induced by dietary restriction and physical exercise in women and BC patients to assess the reduction of $B C$ risk, the decrease of $B C$ recurrence, and the therapeutic potential of food administration [5,36,37]. However, no convincing data have been generated on this topic and no epigenetic biomarkers predictive of the therapeutic efficacy and patient prognosis have been identified as yet. The evaluation of the expression levels of miRNAs modulated by diet and exercise and directly correlated with BC progression and/or therapeutic efficacy may represent an additional strategy to establish patients prognosis, predict cancer recurrence, and evaluate the efficacy of such integrative treatments.

Therefore, the aim of the present study was to computationally select a set of miRNAs strictly involved in $\mathrm{BC}$ development and progression, but also effectively modulated by diet and exercise. For this purpose, the analysis and integration of different BC, diet, and exercise miRNAs expression profiling datasets obtained from the Gene Expression Omnibus DataSets (GEO DataSets; https://www.ncbi.nlm.nih.gov/gds) database was performed. In addition, further bioinformatic prediction analyses were performed on the selected miRNAs in order to establish their prognostic significance and clinical usefulness for BC patients. 
This methodology represents the starting point for novel validation studies performed in BC patients treated with hypocaloric diets or physical activity interventions.

\section{Results}

\section{1. miRNA Microarray Expression Profiling Dataset Selection}

The search of miRNAs expression profiling performed on GEO DataSets allowed for the identification of several datasets containing miRNA expression related to $\mathrm{BC}$, diet, and exercise. By using specific search terms, 229, 47, and 21 miRNA microarray expression profiling datasets were identified for $\mathrm{BC}$, diet, and exercise, respectively. However, following the inclusion and exclusion criteria described in the "Materials and Methods" section, most of these datasets were excluded, thus selecting only eight datasets for BC, three datasets for diet, and eight datasets for exercise (Table 1). The majority of $\mathrm{BC}$ datasets were excluded from the analysis because they contained miRNA expression data obtained from circulating fluids or a limited number of samples, or in vitro or animal models. In the diet and exercise datasets, those containing samples derived from in vitro or animal studies were excluded in order to reduce variability between different species.

The selection of eight different datasets for $\mathrm{BC}$ allowed for the integrated evaluation of miRNA expression levels related to $881 \mathrm{BC}$ samples and 187 normal breast tissue samples (control). In the same manner, the integrated analysis of three miRNA expression datasets related to dietary intervention was carried out on a total of 76 samples of which 38 were before and 38 after dietary intervention. Regarding exercise datasets, the computational analysis was performed on 226 samples of which 114 were before and 112 after physical activities. 
Table 1. Main characteristics of the selected datasets.

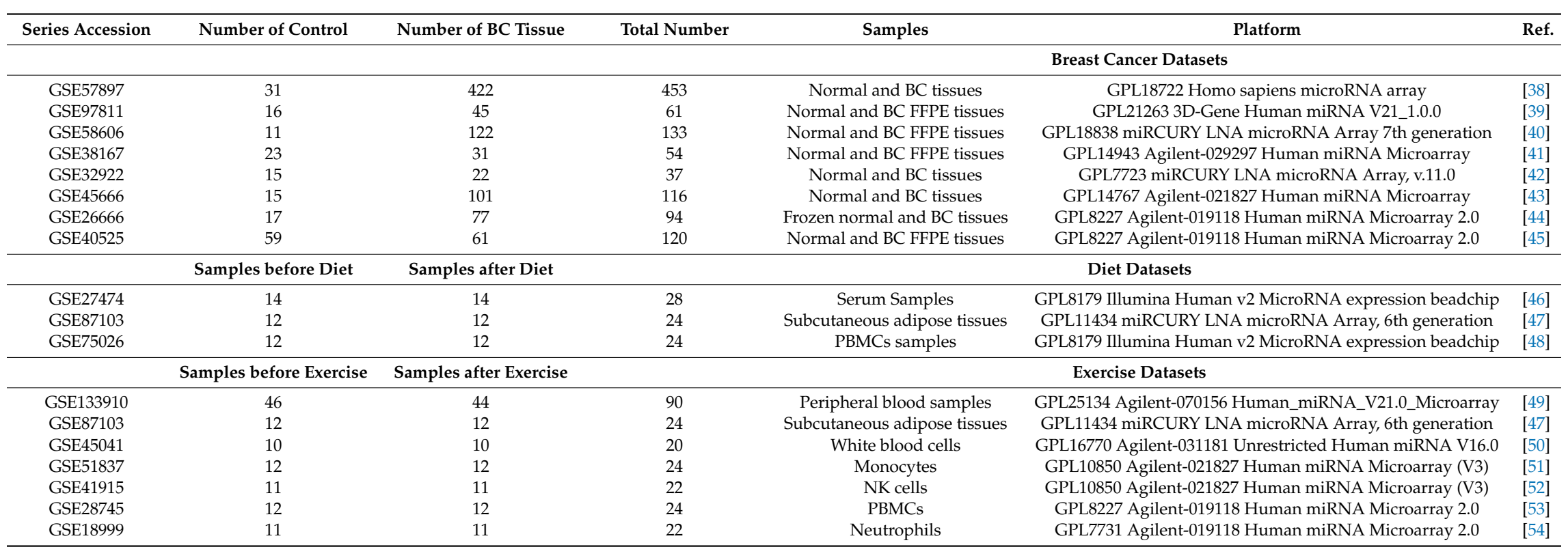




\subsection{Computational Identification of microRNAs Involved in Breast Cancer}

The differential analysis between BC samples and controls performed by using GEO2R allowed for the identification of a list of dysregulated miRNAs for each dataset. In total, a set of 49 miRNAs that were significantly dysregulated $(p<0.01)$ was found in at least five out of the eight datasets selected. Of these miRNAs, 30 were significantly upregulated in BC samples compared to the controls, while 19 were downregulated (Figure 1).

A

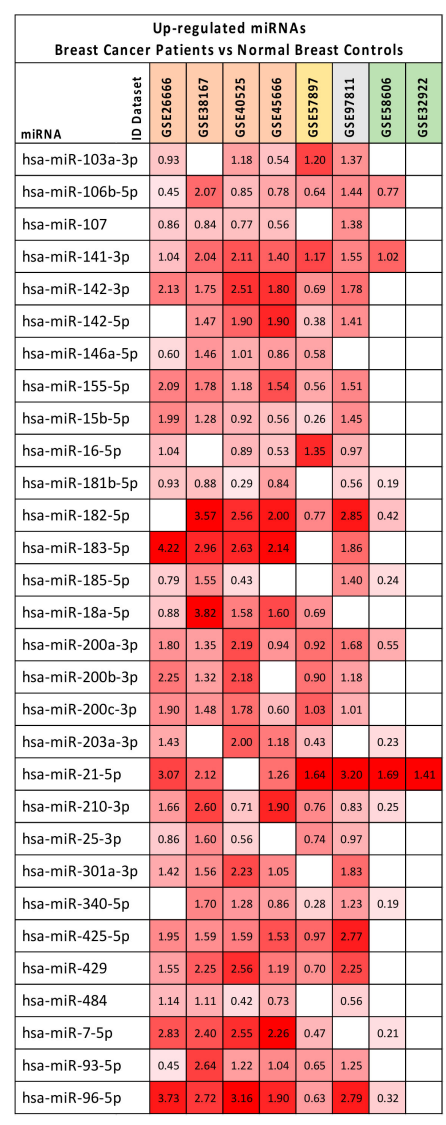

B

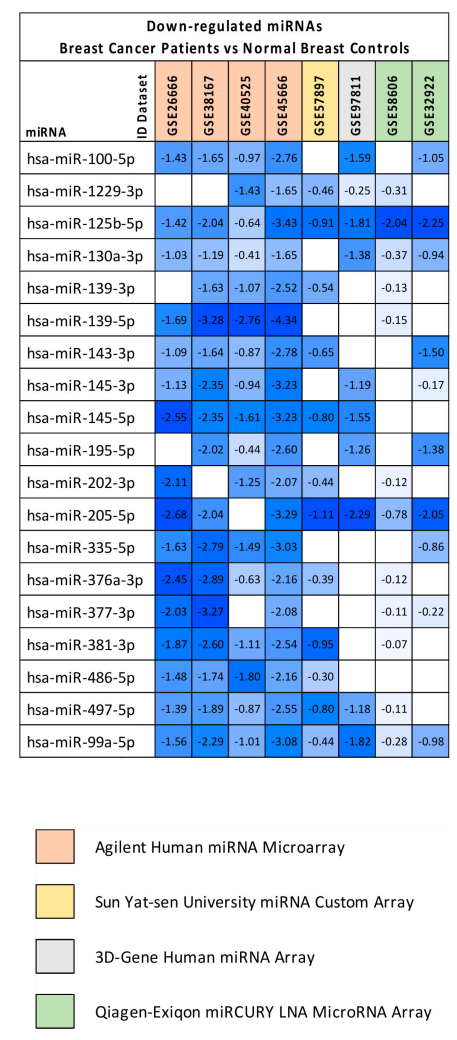

Figure 1. Differentially expressed miRNAs in BC samples compared to normal breast tissues in at least five out of eight datasets. The results of differential analyses were expressed as log2FC values indicating with red scale boxes the upregulated miRNAs (Panel (A)) and with blue scale boxes the downregulated ones (Panel (B)). Dataset IDs were marked with different colors depending on the platform technology used.

Among the upregulated miRNAs, those most commonly altered in the eight datasets and with the highest $\log 2 \mathrm{FC}$ values were hsa-miR-106b-5p, hsa-miR-141-3p, hsa-miR-182-5p, hsa-miR-183-5p, hsa-miR-200 family, hsa-miR-21-5p, hsa-miR-7-5p, and hsa-miR-96-5p. Similarly, among the downregulated miRNAs, the most important were hsa-miR-125b-5p, hsa-miR-123 130a-3p, hsa-miR-139-5p, hsa-miR-205-5p, hsa-miR-497-5p, and hsa-miR-99a-5p. It is important to note that almost all of these miRNAs are known to be involved in several tumors, as will be argued in the Discussion section.

To further corroborate the results obtained from the analysis of the eight GEO DataSets miRNA expression datasets, differential analyses between the expression levels of the miRNAs in BC samples and normal control were performed on the Cancer Genome Atlas Breast Cancer (TCGA BRCA) dataset. As reported in Table 2, this analysis demonstrated that the upregulation and downregulation levels of the 49 significantly dysregulated miRNAs in BC were confirmed for almost all miRNAs selected (Table 2). 
Table 2. Validation of the GEO DataSets selected miRNAs in the Cancer Genome Atlas Breast Cancer database.

\begin{tabular}{|c|c|c|c|}
\hline \multirow{2}{*}{ miRNA } & \multirow{2}{*}{$\begin{array}{c}\text { GEO Datasets log2FC } \\
\text { Average }\end{array}$} & \multicolumn{2}{|c|}{ TCGA BRCA } \\
\hline & & & $p$-Value \\
\hline \multicolumn{4}{|l|}{ Upregulated miRNAs } \\
\hline hsa-miR-103a-3p & 1.044 & 1.532 & $1.031 \times 10^{-19}$ \\
\hline hsa-miR-106b-5p & 1.000 & 2.423 & $7.270 \times 10^{-28}$ \\
\hline hsa-miR-107 & 0.882 & 1.676 & $3.424 \times 10^{-17}$ \\
\hline hsa-miR-141-3p & 1.476 & 5.343 & $2.723 \times 10^{-29}$ \\
\hline hsa-miR-142-3p & 1.775 & 3.040 & $2.214 \times 10^{-18}$ \\
\hline hsa-miR-142-5p & 1.413 & 2.283 & $1.313 \times 10^{-13}$ \\
\hline hsa-miR-146a-5p * & 0.902 & $\# \mathrm{~N} / \mathrm{D}$ & \#N/D \\
\hline hsa-miR-155-5p & 1.443 & 1.961 & $4.674 \times 10^{-18}$ \\
\hline hsa-miR-15b-5p & 1.076 & 1.908 & $1.745 \times 10^{-11}$ \\
\hline hsa-miR-16-5p & 0.955 & 1.591 & $2.960 \times 10^{-8}$ \\
\hline hsa-miR-181b-5p & 0.616 & 2.219 & $1.238 \times 10^{-22}$ \\
\hline hsa-miR-182-5p & 2.027 & 4.799 & $2.421 \times 10^{-40}$ \\
\hline hsa-miR-183-5p & 2.759 & 7.102 & $3.388 \times 10^{-47}$ \\
\hline hsa-miR-185-5p & 0.883 & 1.548 & $2.932 \times 10^{-9}$ \\
\hline hsa-miR-18a-5p & 1.714 & 1.905 & $5.766 \times 10^{-14}$ \\
\hline hsa-miR-200a-3p & 1.346 & 3.948 & $2.352 \times 10^{-26}$ \\
\hline hsa-miR-200b-3p & 1.564 & 2.846 & $4.468 \times 10^{-20}$ \\
\hline hsa-miR-200c-3p & 1.298 & 2.691 & $2.049 \times 10^{-17}$ \\
\hline hsa-miR-203a-3p & 1.055 & 2.287 & $2.680 \times 10^{-14}$ \\
\hline hsa-miR-21-5p & 2.054 & 4.448 & $5.680 \times 10^{-41}$ \\
\hline hsa-miR-210-3p & 1.244 & 5.632 & $1.111 \times 10^{-31}$ \\
\hline hsa-miR-25-3p * & 0.946 & $\# \mathrm{~N} / \mathrm{D}$ & \#N/D \\
\hline hsa-miR-301a-3p & 1.620 & 2.314 & $7.058 \times 10^{-24}$ \\
\hline hsa-miR-340-5p & 0.924 & 2.001 & $8.384 \times 10^{-25}$ \\
\hline hsa-miR-425-5p & 1.733 & 1.740 & $8.393 \times 10^{-8}$ \\
\hline hsa-miR-429 & 1.751 & 4.884 & $6.208 \times 10^{-33}$ \\
\hline hsa-miR-484 & 0.792 & 1.399 & $2.801 \times 10^{-6}$ \\
\hline hsa-miR-7-5p & 1.786 & 1.850 & $7.483 \times 10^{-21}$ \\
\hline hsa-miR-93-5p & 1.209 & 2.110 & $5.223 \times 10^{-26}$ \\
\hline hsa-miR-96-5p & 2.178 & 6.970 & $7.515 \times 10^{-47}$ \\
\hline \multicolumn{4}{|c|}{ Downregulated miRNAs } \\
\hline hsa-miR-100-5p & -1.574 & -4.066 & $1.191 \times 10^{-52}$ \\
\hline hsa-miR-1229-3p & -0.819 & 1.274 & $2.105 \times 10^{-6}$ \\
\hline hsa-miR-125b-5p & -1.819 & -4.107 & $6.680 \times 10^{-48}$ \\
\hline hsa-miR-130a-3p & -0.996 & -2.371 & $2.085 \times 10^{-30}$ \\
\hline hsa-miR-139-3p & -1.178 & -8.512 & $2.131 \times 10^{-52}$ \\
\hline hsa-miR-139-5p & -2.444 & -8.699 & $6.482 \times 10^{-58}$ \\
\hline hsa-miR-143-3p & -1.422 & -2.288 & $1.458 \times 10^{-28}$ \\
\hline hsa-miR-145-3p & -1.501 & -3.196 & $7.255 \times 10^{-54}$ \\
\hline hsa-miR-145-5p & -2.015 & -5.892 & $2.501 \times 10^{-50}$ \\
\hline hsa-miR-195-5p & -1.541 & -2.867 & $1.560 \times 10^{-39}$ \\
\hline hsa-miR-202-3p * & -1.198 & \#N/D & \#N/D \\
\hline hsa-miR-205-5p & -2.033 & -5.921 & $4.198 \times 10^{-35}$ \\
\hline hsa-miR-335-5p & -1.961 & -4.846 & $4.980 \times 10^{-27}$ \\
\hline hsa-miR-376a-3p & -1.441 & -1.364 & $2.287 \times 10^{-8}$ \\
\hline hsa-miR-377-3p & -1.542 & -1.418 & $2.186 \times 10^{-7}$ \\
\hline hsa-miR-381-3p & -1.523 & -2.486 & $3.350 \times 10^{-26}$ \\
\hline hsa-miR-486-5p & -1.496 & -10.611 & $3.737 \times 10^{-26}$ \\
\hline hsa-miR-497-5p & -1.254 & -2.726 & $1.543 \times 10^{-33}$ \\
\hline hsa-miR-99a-5p & -1.433 & -5.165 & $6.270 \times 10^{-63}$ \\
\hline
\end{tabular}

* Non-significantly dysregulated miRNAs in the TCGA BRCA database; in bold miRNAs with discordant expression levels between the GEO DataSets and TCGA databases. 
Of note, the most upregulated (e.g., hsa-miR-182-5p, hsa-miR-183-5p, hsa-miR-21-5p) and downregulated (e.g., hsa-miR-139-5p, hsa-miR-145-3p, hsa-miR-205-5p) miRNAs in the GEO DataSets microarray platforms were also strongly dysregulated in the TCGA BRCA database. In addition, among the 49 selected GEO DataSets miRNAs, three miRNAs (i.e., hsa-miR-146a-5p, hsa-miR-25-3p and miR-202-3p) showed no alteration of their expression in TCGA BRCA database, while the hsa-miR-1229-3p was downregulated in the GEO DataSets platforms and upregulated in TCGA BRCA database. Overall, these results further confirm the robustness of the computational analyses performed on the GEO DataSets for BC.

\subsection{Computational Identification of microRNA Modulated by Diet and Exercise}

As described for BC datasets, the GEO2R differential analyses performed for diet and exercise datasets revealed that these interventions may beneficially modulate some miRNAs. In particular, 10 dysregulated miRNAs were found when merging the seven exercise datasets selected. Of these, five were upregulated and five downregulated (Figure 2A).
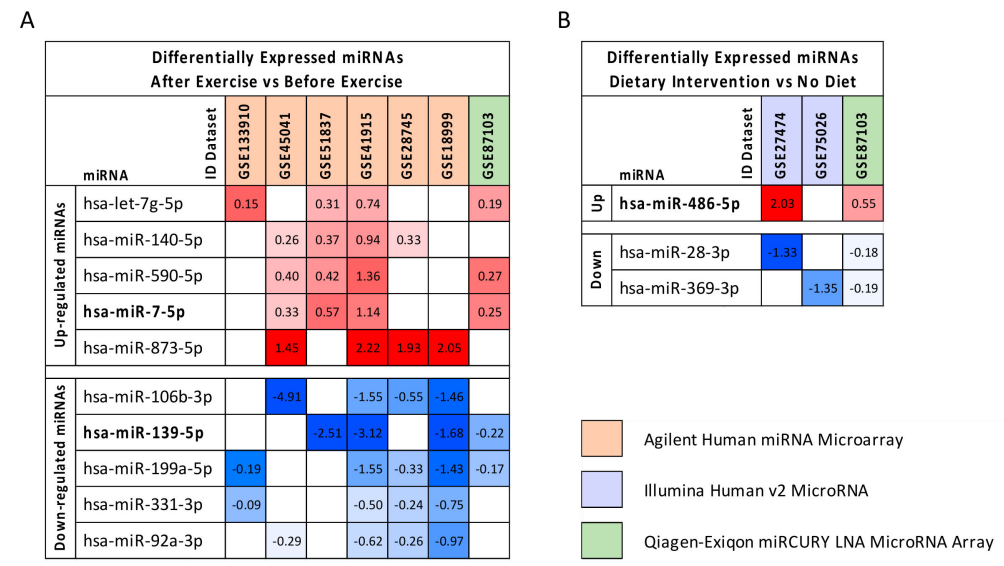

Figure 2. Panel (A): Differentially expressed miRNAs before and after exercise. Panel (B): Differentially expressed miRNAs before and after dietary interventions. miRNAs in common in at least $>50 \%$ of the selected datasets were selected. The results of the differential analyses were expressed as $\log 2 \mathrm{FC}$ values indicating with red scale boxes the upregulated miRNAs and blue scale boxes the downregulated ones. Dataset IDs were marked with different colors depending on the platform technology used. In bold are reported miRNAs also involved in BC.

In the same manner, three deregulated miRNAs, one upregulated and two downregulated, were identified by analyzing the three diet datasets alone (Figure 2B).

It is important to note that some of these miRNAs were also deregulated in BC. In particular, hsa-miR-486-5p and hsa-miR-7-5p were significantly upregulated by diet and exercise, respectively. These miRNAs were also downregulated and upregulated, respectively, in the BC dataset. Similarly, hsa-miR-139-5p was significantly downregulated by exercise and also downregulated in BC.

\subsection{Breast Cancer (BC) miRNA Modulation of Epithelial-Mesenchymal Transition (EMT) Genes}

As expected, the gene expression profiling interactive analysis (GEPIA) showed that the majority of epithelial-mesenchymal transition (EMT) genes were significantly deregulated in breast cancer samples compared to controls reflecting an epithelial phenotype. Overall, almost all the EMT genes analyzed were downregulated in breast cancer samples compared to normal breast tissues, except for CDH1, CTNNB1, and CDH2 that were upregulated in BC. However, of these, only CDH1 was statistically upregulated. On the contrary, significantly downregulated EMT genes in thee BC samples were TWIST1, TWIST2, ZEB1, ZEB2, and VIM (Figure 3). 

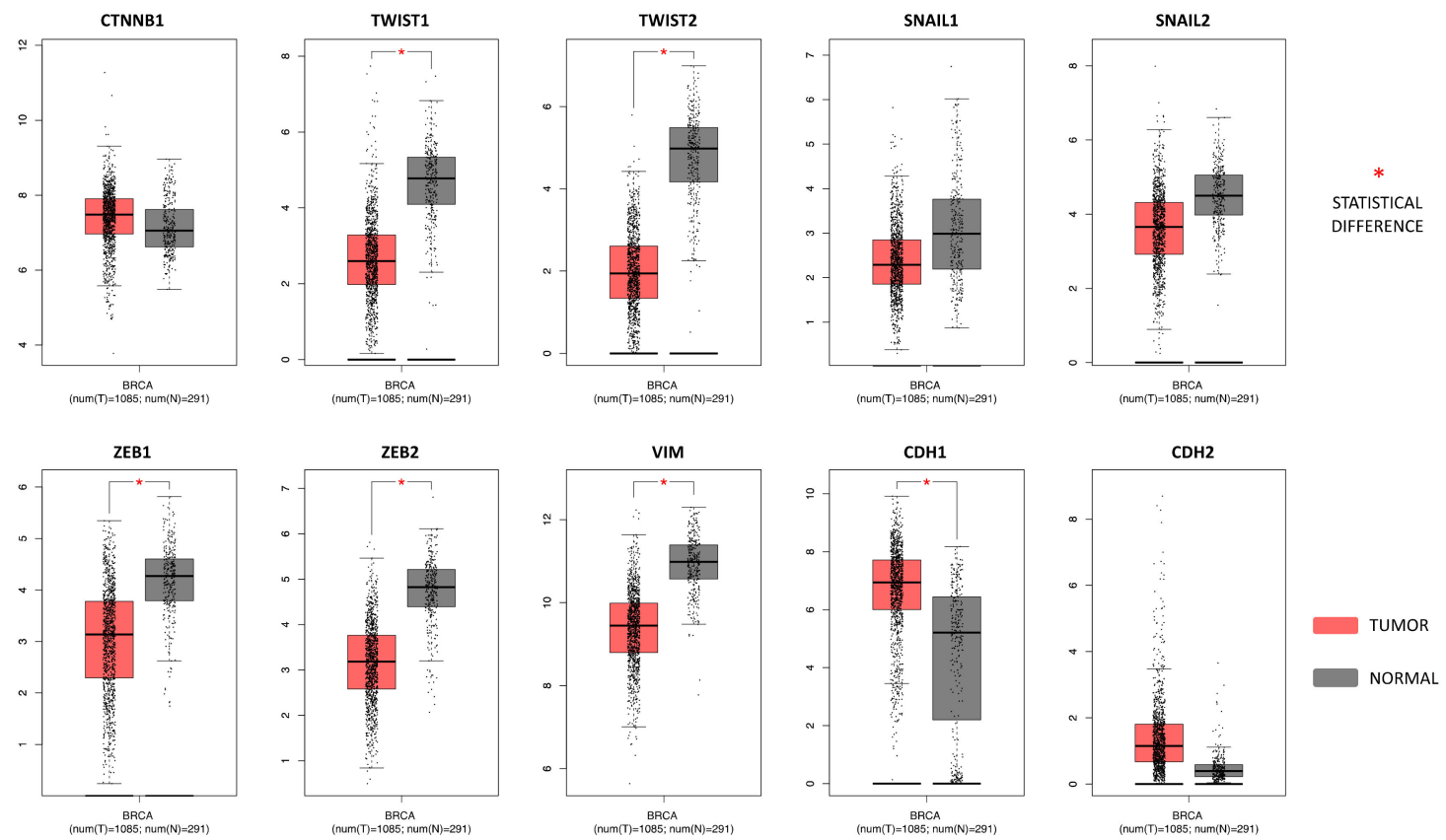

Figure 3. EMT gene expression levels in breast cancer samples compared to the controls. The GEPIA software performs a four-way ANOVA differential analysis (using sex, age, ethnicity, and disease state (tumor or normal) as variables for calculating differential expression. The $p$-values were adjusted according to the Benjamini and Hochberg false discovery rate. The $p$-value threshold was set at 0.01 $\left.{ }^{*}=p<0.01\right)$. The relative expression levels were first $\log 2(\mathrm{TPM}+1)$ transformed and the $\log 2 \mathrm{FC}$ was defined as median (Tumor)—Median (Normal), where TPM is the transcript count per million.

After GEPIA, the mirDIP prediction tool was used to identify the level of interaction between the computationally selected miRNAs strongly involved in BC development and the main genes involved in EMT.

The mirDIP analysis showed that all 49 deregulated miRNAs in BC were able to interact with the 10 genes previously analyzed.

As reported in Figure 4, all selected miRNAs were able to target the EMT genes with interaction levels ranging from low to very high. Some genes were shown to be strongly modulated by the upregulated miRNAs. In particular, the CTNNB1, SNAIL2, ZEB1, and ZEB2 EMT genes showed the highest interaction levels with the upregulated miRNAs; in addition, ZEB1 and ZEB2 also showed very high interaction levels with some of the downregulated miRNAs. Generally, the upregulated miRNAs showed higher interaction levels with the EMT genes compared to the downregulated miRNAs. Of these miRNAs, the upregulated hsa-miR-106b-5p, hsa-miR-146a-5p, hsa-miR-203a-5p, and hsa-miR-25-3p showed very high interaction levels with almost all the EMT genes analyzed, suggesting that the modulation of these miRNAs may play a fundamental role in the regulation of cancer progression and in the development of the EMT phenotype. In contrast, the TWIST1 and TWIST2 genes showed the lowest interaction levels with all miRNAs (Figure 4). 
A

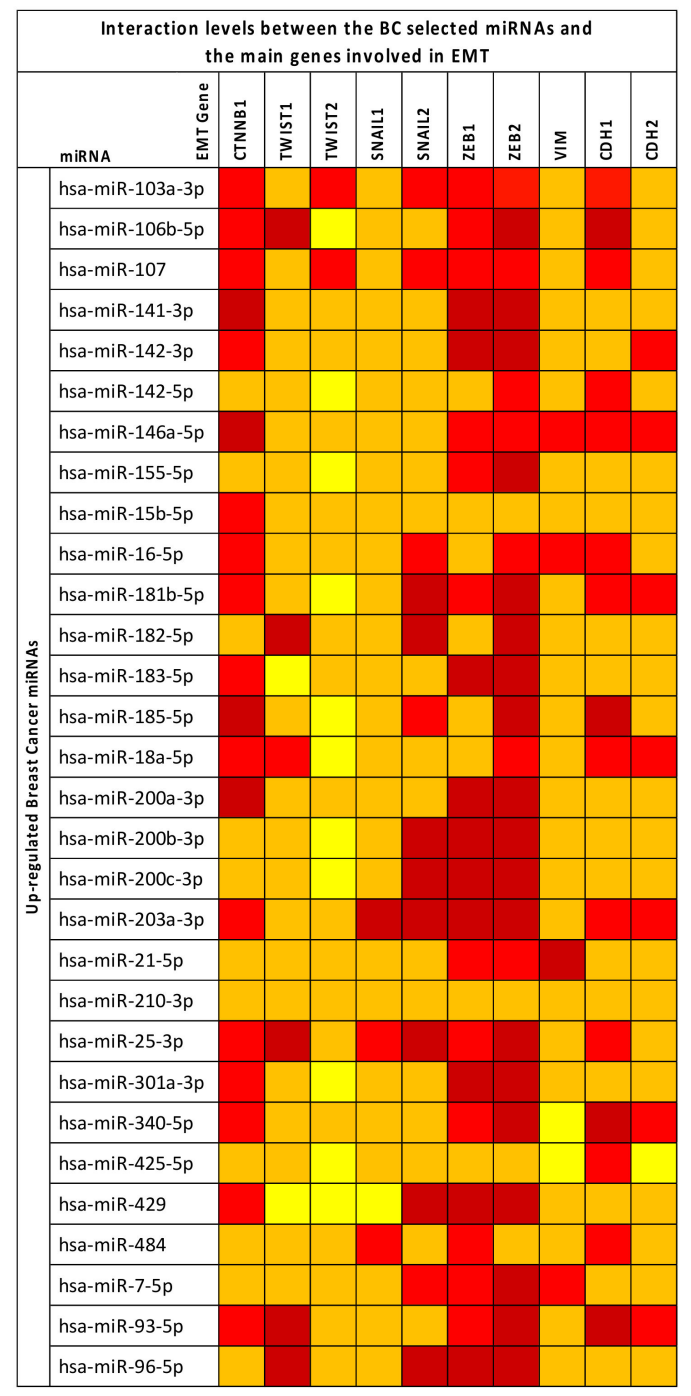

B
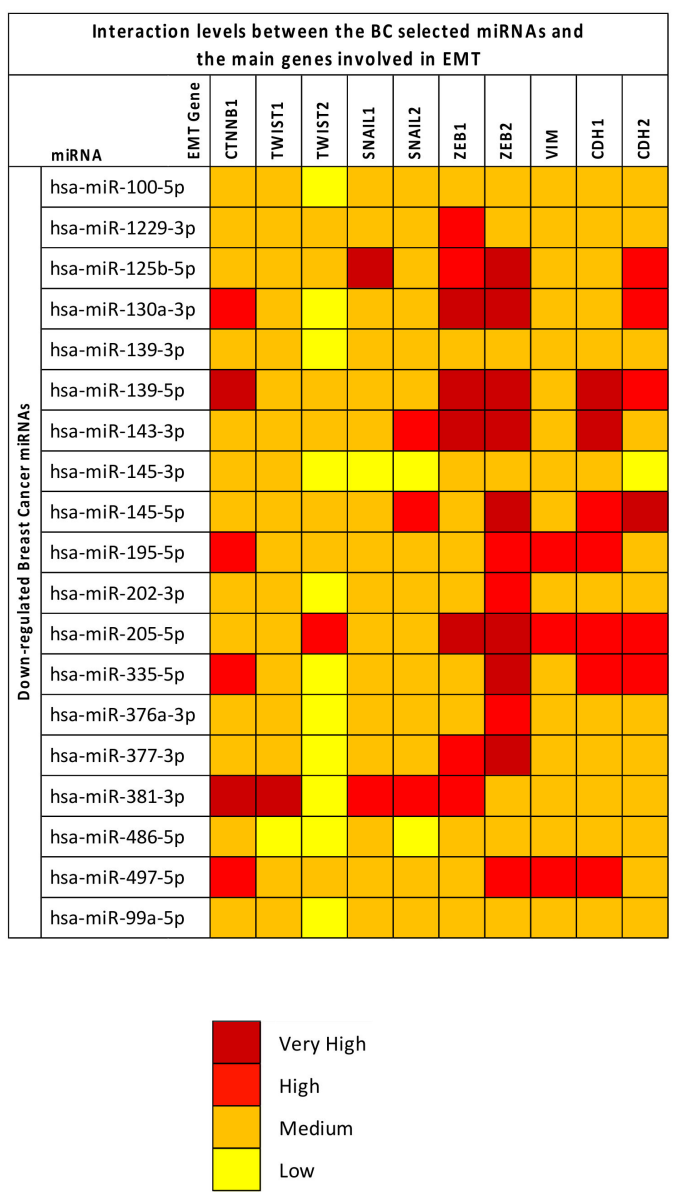

Figure 4. mirDIP analysis of BC miRNAs and EMT genes. Panel (A): Interaction between BC upregulated miRNAs and EMT genes. Panel (B): Interaction between BC downregulated miRNAs and EMT gene. The intensity of miRNA-gene interactions is reported as a red color scale ranging from yellow (low interaction levels) and dark red (very high interaction levels). Each EMT gene is reported with the level of interaction with the computationally selected BC miRNAs.

The same mirDIP analysis on EMT genes was performed for the miRNAs selected by analyzing the diet and exercise datasets. Furthermore these miRNAs, particularly those obtained from the exercise datasets, were able to highly interact with the aforementioned EMT genes such as SNAIL2, ZEB1, and ZEB2. The most evident interactions were mediated by the upregulated hsa-miR-140-5p and the downregulated hsa-miR-139-5p, hsa-miR-199a-5p, and hsa-miR-92a-3p (Figure 5). 
A

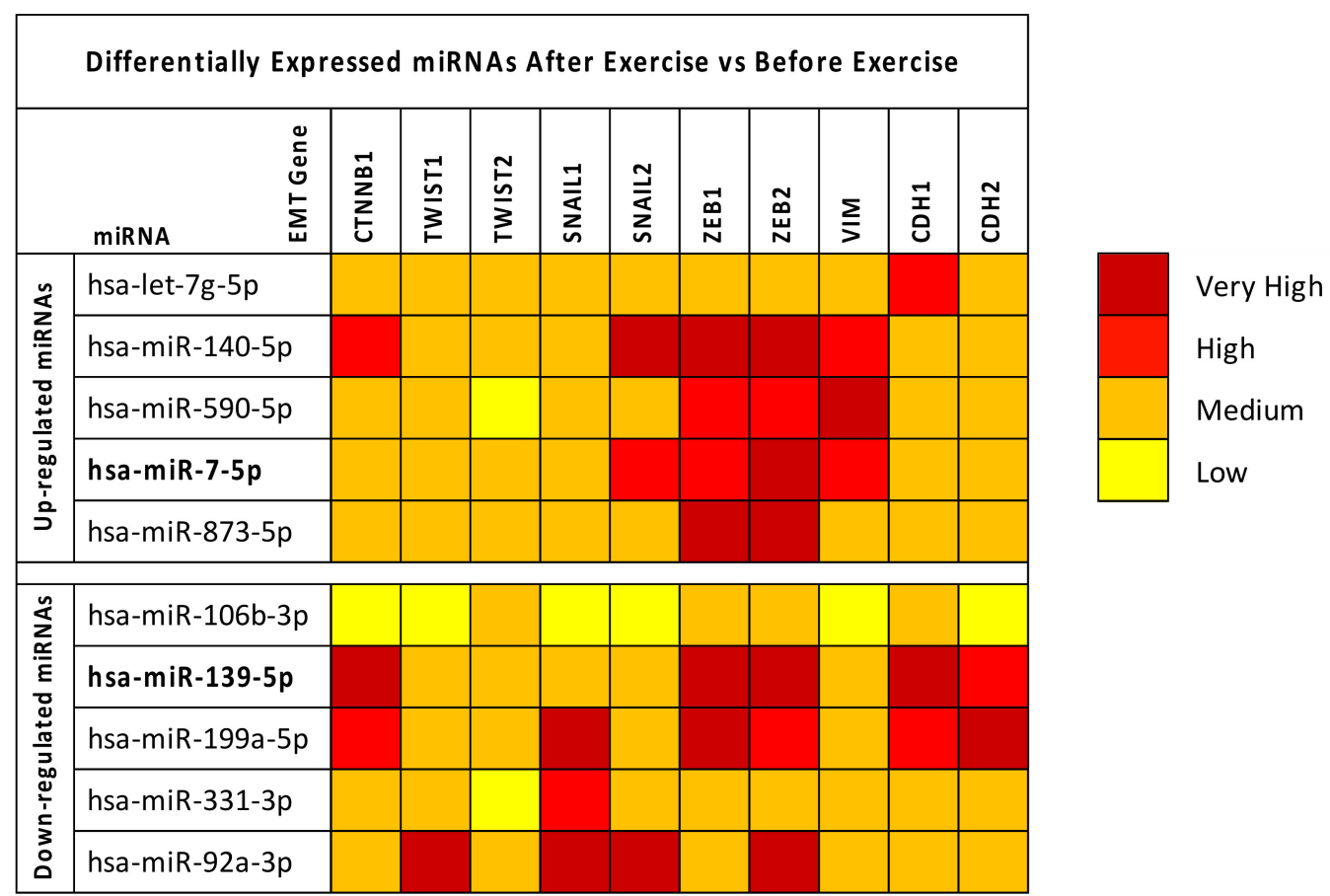

$\mathrm{B}$ Differentially Expressed miRNAs Dietary Intervention vs No Diet

\begin{tabular}{|c|c|c|c|c|c|c|c|c|c|c|c|}
\hline \multicolumn{2}{|r|}{ miRNA } & 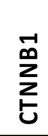 & 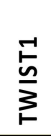 & $\stackrel{\mathfrak{n}}{n}$ & $\underset{n}{\stackrel{J}{\pi}}$ & 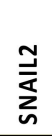 & $\begin{array}{l}\overrightarrow{0} \\
\stackrel{W}{N}\end{array}$ & $\underset{\tilde{N}}{\stackrel{N}{N}}$ & $\sum_{j}$ & $\begin{array}{l}\overrightarrow{1} \\
\text { ป̂ }\end{array}$ & 꽁 \\
\hline$\stackrel{2}{3}$ & hsa-miR-486-5p & & & & & & & & & & \\
\hline \multirow{2}{*}{$\begin{array}{l}\text { zo } \\
\text { 口́ }\end{array}$} & hsa-miR-28-3p & & & & & & & & & & \\
\hline & hsa-miR-369-3p & & & & & & & & & & \\
\hline
\end{tabular}

Figure 5. Panel (A): Interaction levels between EMT genes and miRNAs modulated by exercise. Panel (B): Interaction levels between EMT genes and miRNAs modulated by diet. The intensity of miRNA-gene interactions is reported as a red color scale ranging from yellow (low interaction levels) and dark red (very high interaction levels). For each EMT gene is reported the level of interaction with the computationally selected BC miRNAs.

Contrary to what was observed for BC miRNAs, in this case, the highest interactions were found between downregulated miRNAs and EMT genes, especially with regard to diet-modulated miRNAs. Therefore, these results suggest that lifestyle interventions, and in particular dietary interventions, may represent a good therapeutic strategy aimed at reducing cancer aggressiveness, thus limiting the mesenchymal transformation of cancer cells.

\section{5. microRNA Pathway Prediction Analysis and miRNA-Targeted Genes Protein-Protein Interaction}

The DIANA-mirPath analysis performed on the 10 miRNAs modulated by exercise showed that, globally, these miRNAs were able to alter 59 different molecular and signaling transduction pathways deposited on Kyoto Encyclopedia of Genes and Genomes (KEGG) and involved in different cellular processes (data not shown). Specifically, these miRNAs were able to modulate 35 different pathways and 2006 genes directly and indirectly involved in cancer development and progression (Table 3). 
Table 3. Molecular and signaling transduction pathways altered by the 10 miRNAs modulated by exercise and involved in cancer.

\begin{tabular}{|c|c|c|c|}
\hline KEGG Pathway & $p$-Value & N. of Targeted Genes & Involved miRNAs \\
\hline Pathways in cancer (hsa05200) & $4.05564 \times 10^{-7}$ & 179 & 10 \\
\hline PI3K-Akt signaling pathway (hsa04151) & 0.011123026 & 140 & 10 \\
\hline Proteoglycans in cancer (hsa05205) & $2.21725 \times 10^{-17}$ & 107 & 10 \\
\hline MAPK signaling pathway (hsa04010) & 0.011123026 & 104 & 10 \\
\hline Viral carcinogenesis (hsa05203) & $6.08511 \times 10^{-8}$ & 95 & 10 \\
\hline Transcriptional misregulation in cancer (hsa05202) & 0.002760238 & 80 & 10 \\
\hline Hippo signaling pathway (hsa04390) & $1.31008 \times 10^{-8}$ & 76 & 10 \\
\hline FoxO signaling pathway (hsa04068) & $1.48491 \times 10^{-6}$ & 71 & 10 \\
\hline Cell cycle (hsa04110) & $3.14391 \times 10^{-5}$ & 66 & 10 \\
\hline Insulin signaling pathway (hsa04910) & 0.009388457 & 65 & 10 \\
\hline AMPK signaling pathway (hsa04152) & 0.006097228 & 62 & 10 \\
\hline Thyroid hormone signaling pathway (hsa04919) & 0.000182888 & 61 & 10 \\
\hline HIF-1 signaling pathway (hsa04066) & $3.77879 \times 10^{-5}$ & 57 & 10 \\
\hline TNF signaling pathway (hsa04668) & 0.014299582 & 54 & 10 \\
\hline Prostate cancer (hsa05215) & $2.74229 \times 10^{-5}$ & 52 & 10 \\
\hline Small cell lung cancer (hsa05222) & $2.1672 \times 10^{-5}$ & 50 & 10 \\
\hline Estrogen signaling pathway (hsa04915) & 0.00014031 & 47 & 10 \\
\hline ErbB signaling pathway (hsa04012) & 0.001313884 & 45 & 9 \\
\hline Chronic myeloid leukemia (hsa05220) & $1.45098 \times 10^{-6}$ & 44 & 10 \\
\hline Renal cell carcinoma (hsa05211) & $1.69642 \times 10^{-7}$ & 42 & 10 \\
\hline TGF-beta signaling pathway (hsa04350) & $4.62474 \times 10^{-6}$ & 41 & 10 \\
\hline Pancreatic cancer (hsa05212) & $9.61555 \times 10^{-6}$ & 40 & 10 \\
\hline Colorectal cancer (hsa05210) & $5.0244 \times 10^{-7}$ & 39 & 10 \\
\hline p53 signaling pathway (hsa04115) & 0.00014031 & 39 & 10 \\
\hline Apoptosis (hsa04210) & 0.018765462 & 38 & 10 \\
\hline Glioma (hsa05214) & $2.56338 \times 10^{-6}$ & 37 & 10 \\
\hline Central carbon metabolism in cancer (hsa05230) & $2.56338 \times 10^{-6}$ & 36 & 10 \\
\hline Non-small cell lung cancer (hsa05223) & $8.72499 \times 10^{-6}$ & 34 & 10 \\
\hline ECM-receptor interaction (hsa04512) & $1.96805 \times 10^{-5}$ & 34 & 10 \\
\hline mTOR signaling pathway (hsa04150) & 0.003253273 & 34 & 10 \\
\hline Melanoma (hsa05218) & 0.009412459 & 34 & 10 \\
\hline Endometrial cancer (hsa05213) & $3.18028 \times 10^{-5}$ & 32 & 10 \\
\hline Acute myeloid leukemia (hsa05221) & 0.019544711 & 29 & 10 \\
\hline Bladder cancer (hsa05219) & 0.000423154 & 25 & 9 \\
\hline Thyroid cancer (hsa05216) & 0.000804104 & 17 & 10 \\
\hline
\end{tabular}

Of these pathways, the most important and highly modulated were the following KEGG pathways: "Pathways in cancer (hsa05200)", "Proteoglycans in cancer (hsa05205)", “MAPK signaling pathway (hsa04010)", and "PI3K-Akt signaling pathway (hsa04151)". All these pathways are known to be altered in cancer including that of the breast. Overall, exercise is able to modulate 652 univocal genes through the modulation of the 10 computationally identified miRNAs. These results suggest that exercise may play a key role in counteracting cancer progression, in line with current evidence in vivo, and in support of the therapeutic efficacy of standard anticancer treatments. Indeed, among these genes, the most frequently altered within the 35 identified KEGG pathways were MAPK1 (27 out of 35 pathways), AKT1, AKT2, PIK3CA, PIK3CB, PIK3R3 (26 out of 35), AKT3, KRAS (23 out of 35), CCND1, TP53 (22 out of 35), HRAS, MAP2K2, NRAS, RAF1 (21 out of 35), BRAF (19 out of 35), and MYC (18 out of 35).

Overall, these miRNAs were potentially involved in the modulation of the MAPK family (including RAS/RAF/MAPK genes); Caspase family (strongly involved in apoptosis), Cyclin/CDK family; transcription factors; epidermal-, vascular endothelial-, fibroblast-, and platelet-derived growth factors; and the SMAD family, among others.

Regarding the three miRNAs directly modulated by diet, the DIANA-mirPath analysis revealed that diet-modulated miRNAs were able to modulate five different KEGG pathways: Adherens junction (hsa04520), Choline metabolism in cancer (hsa05231), Epithelial cell signaling in Helicobacter pylori infection (hsa05120), Colorectal cancer (hsa05210), and Glioma (hsa05214) (Table 4). 
Table 4. KEGG pathways altered by the three miRNAs modulated by diet.

\begin{tabular}{cccc}
\hline KEGG Pathway & $p$-Value & N. of Targeted Genes & Involved miRNAs \\
\hline Adherens junction (hsa04520) & 0.00127981 & 10 & 2 \\
\hline Choline metabolism in cancer (hsa05231) & 0.0417592 & 10 & 2 \\
\hline $\begin{array}{c}\text { Epithelial cell signaling in Helicobacter } \\
\text { pylori infection (hsa05120) }\end{array}$ & 0.04463459 & 9 & 2 \\
\hline Colorectal cancer (hsa05210) & 0.02665458 & 8 & 3 \\
\hline Glioma (hsa05214) & 0.02665458 & 7 & 3 \\
\hline
\end{tabular}

Overall, these miRNAs were able to modulate 44 genes of which 28 were univocal. Among these genes, the most frequently altered were EGFR and RAC1 (four out of five pathways), PLCG1 (three out of five), FOS, MET, NRAS, SMAD4, SOS2, TGFBR2, WASF1, and WASL (two out of five).

Although to a lesser extent than exercise, those miRNAs also directly modulated by diet were able to alter several KEGG pathways and, in turn, key tumor suppressors and oncogenes involved in cancer progression. In particular, diet-modulated miRNAs were able to target and interfere with several genes mainly involved in cancer signal transduction pathways (e.g., EGFR, RAC1, PLCG1, FOS, NRAS, SOS2, etc.).

To further corroborate these DIANA-mirPath results, Search Tool for the Retrieval of Interacting Genes/Proteins (STRING) and Gene Ontology (GO) analyses were performed to cluster the 652 univocal genes targeted by exercise-modulated miRNAs. In the STRING analysis, the high number of genes identified does not permit a clear clustering of all hubs and networks among genes to be obtained. Nevertheless, it showed that those genes were involved in 203 pathways and, in particular, 61 of them were strongly involved in the breast cancer KEGG pathway (hsa05224) (Figure 6).

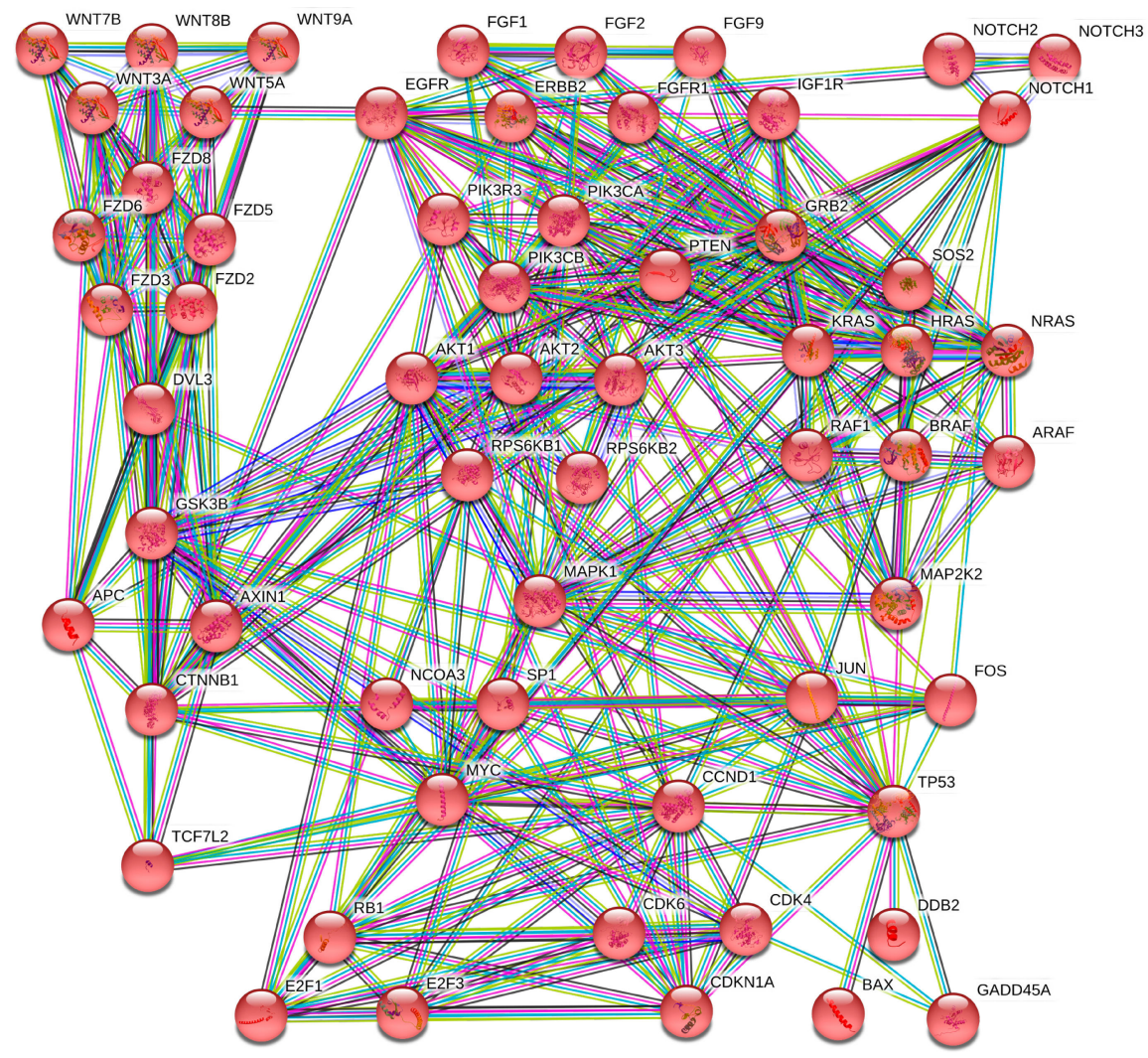

Figure 6. STRING protein interaction network of 61 out of 652 genes targeted by the selected miRNAs and directly involved in the breast cancer KEGG pathway (hsa05224). 
In Figure 6, it is possible to note that the exercise-modulated miRNAs were able to modulate genes, and consequently proteins, at all levels of a signal transduction pathway. Overall, the computationally selected miRNAs were able to significantly alter the Wnt/B-catenin pathway, the MAPKs pathway, and the PI3K/Akt pathway by altering ligands (FGF and WNT families), receptors (EGFR, ERBB2, FGFR1, IGFR1, NOTCH family, and FZD receptors), intracellular tyrosine kinases (PI3K family, AKT family, RAS and RAF family, etc.), transcription factors (E2F family), and finally, effectors.

The same STRING analysis was performed for the 28 univocal genes altered by diet-modulated miRNAs. In this case, STRING protein-protein interactions showed that the 28 proteins derived from the selected genes were able to alter 125 different KEGG pathways. Eight out of 28 proteins were also involved in the breast cancer pathway (hsa05224) and these proteins refer to EGFR and RAS signal transduction pathways, thus including proteins like EGFR, NRAS, PTEN, RPS6KB1, SP1, SOS2, FOS, and E2F2 transcription factor (Figure 7).

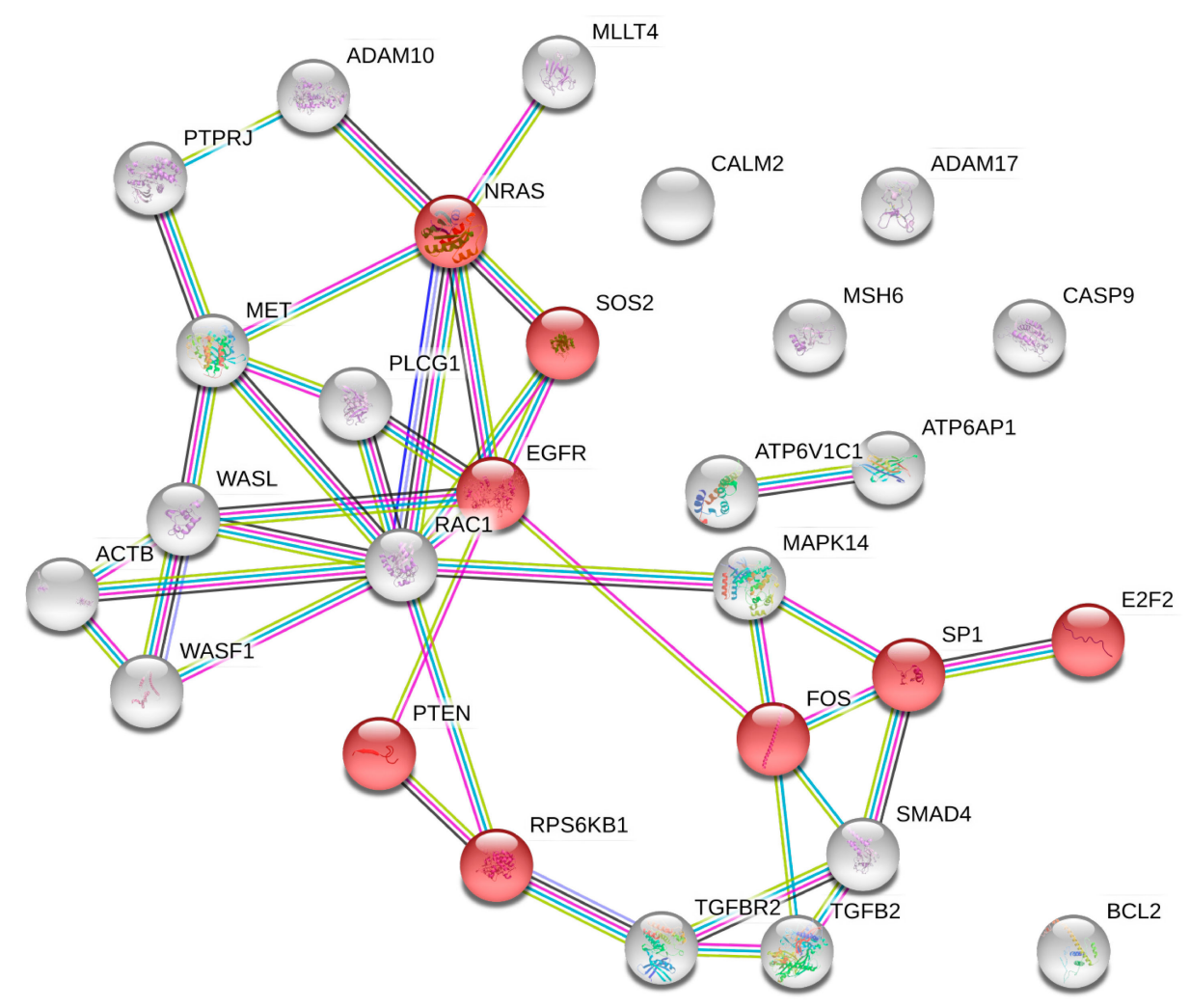

Figure 7. STRING interaction network between genes targeted by the diet-modulated miRNAs. In red are the genes involved in the breast cancer KEGG pathway (hsa05224).

By merging the 652 exercise-modulated and the 28 diet-modulated genes, it was possible to identify 17 genes modulated by both diet and exercise and involved in several cancer pathways including that of BC.

In order to establish the functional role of the 652 exercise-modulated and the 28 diet-modulated genes, GO Panther analyses were performed to cluster such genes according to their Molecular Function, Biological Process, and Cellular Component.

The two independent GO Panther analyses performed on exercise- and diet-modulated genes showed that, overall, the genes identified were involved in the same molecular functions and biological processes and were part of the same cellular component (Figure 8). 

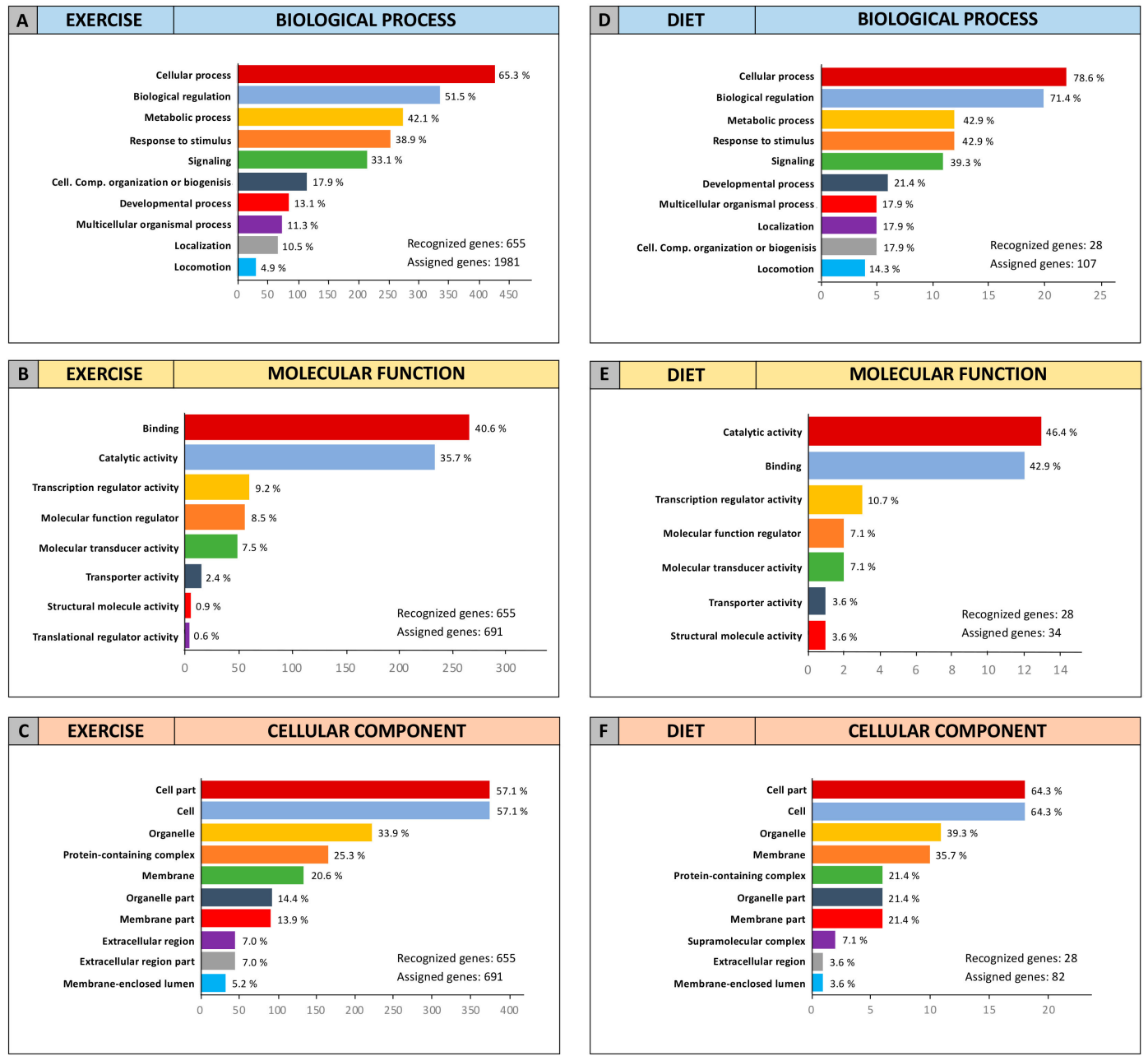

Figure 8. STRING and Gene Ontology (GO) enrichment analyses of exercise- and diet-miRNA-modulated genes. (A) Exercise-modulated genes clustered according to biological process; (B) exercise-modulated genes clustered according to molecular function; (C) exercise-modulated genes clustered according to cellular component; (D) diet-modulated genes clustered according to biological process; (E) diet-modulated genes clustered according to molecular function; and (F) diet-modulated genes clustered according to cellular component.

As shown in Figure 8, for the "Biological Process" category, the majority of exercise- and diet-modulated genes were involved in cellular process, biological regulation, metabolic process, response to stimulus, and in cellular signaling (Figure 8A,D). Concordant results were also obtained for the "Molecular Function" category, showing that almost 90\% of exercise- and diet-modulated genes were involved in binding and catalytic activities as well as, to a lesser extent, transcriptional regulation (Figure 8B,E). Finally, the analysis of the "Cellular Component" category showed that the computationally identified genes were all part of the cell compartment, especially the cell, organelle, and membrane. However, genes also belonging to the extracellular region including ligands and growth factors were represented within both exercise- and diet-modulated genes (Figure 8C,F).

Overall, STRING and GO Panther analyses revealed that the miRNAs modulated by both diet and exercise induced the strong modulation of the main pathways and genes involved in key cellular processes responsible for $\mathrm{BC}$ development and therapeutic failure. Therefore, these encouraging results suggest how a healthy lifestyle and diet may positively influence the outcome of breast cancer patients after surgery. 


\subsection{Overall Survival Predictive Value of BC, Exercise-Modulated, and Diet-Modulated microRNAs}

The OncoLnc analysis performed on the 49 BC miRNAs, the 10 exercise-modulated miRNAs, and the three diet-modulated miRNAs allowed for the identification of a miRNAs signature able to predict the prognosis of $\mathrm{BC}$ patients with respect to OS, taking into account the survival data contained in TCGA BRCA database.

The OncoLnc analysis performed on the 49 BC miRNAs revealed that only five miRNAs were statistically associated with a lower OS (log-rank test, $p<0.05$ ). Of these miRNAs, four were upregulated (hsa-miR-484, hsa-miR-185-5p, hsa-miR-340-5p, and hsa-miR-146a-5p) and only one, the hsa-miR-195-5p, was downregulated (Figure 9).

A

Up-regulated microRNAs
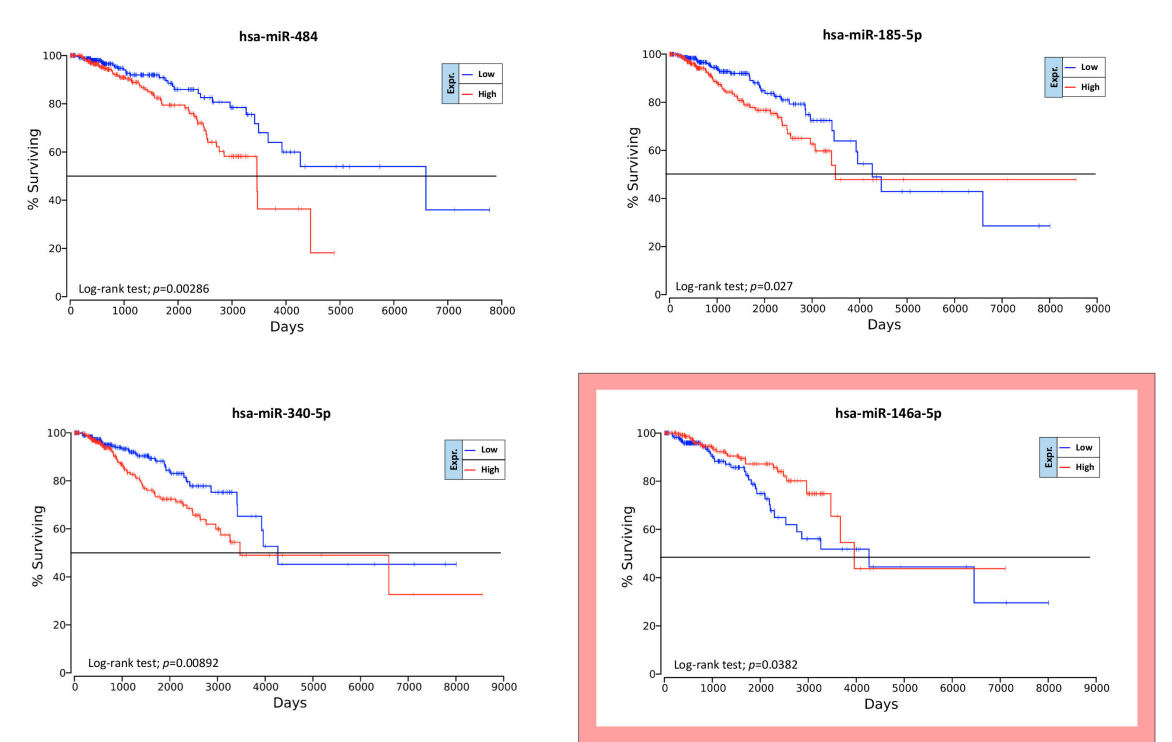

B

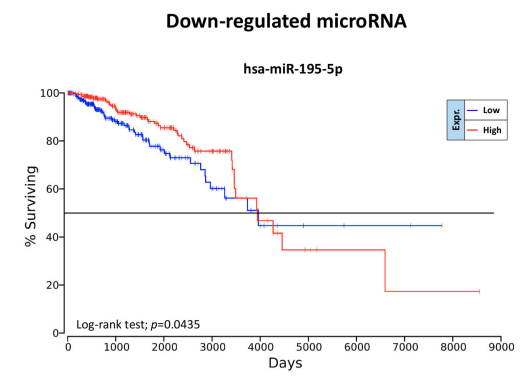

Figure 9. Prognostic value of BC dysregulated miRNAs according to OncoLnc. Panel (A): Upregulated miRNAs statistically associated with the survival of patients. In the red box is reported the upregulated miRNA whose expression is not concordant with survival curves. Panel (B): downregulated BC miRNA statistically associated with the survival of patients.

As shown in Figure 9A, one of the four upregulated miRNAs, the miRNA hsa-miR-146a-5p showed ambiguous results. Despite this miRNA being over-expressed in BC samples compared to controls, its upregulation was associated with a better prognosis (Figure 9A).

Contrary to what was observed for the BC-associated miRNAs, no evidence was shown for the possible prognostic value of exercise- and diet-modulated miRNAs. In particular, none of the computationally selected miRNAs showed statistical significance with respect to OS. However, some miRNAs downregulated by exercise showed a weak association with the survival of BC patients. In particular, hsa-miR-139-5p and hsa-miR-331-3p downregulated by exercise showed interesting results (Figure 10). Indeed, although not statistically significant, these two downregulated miRNAs 
were associated with a better prognosis for BC patients. Therefore, an integrated treatment including exercise and/or diet that is able to downregulate these miRNAs may lead to a better prognosis for BC patients.
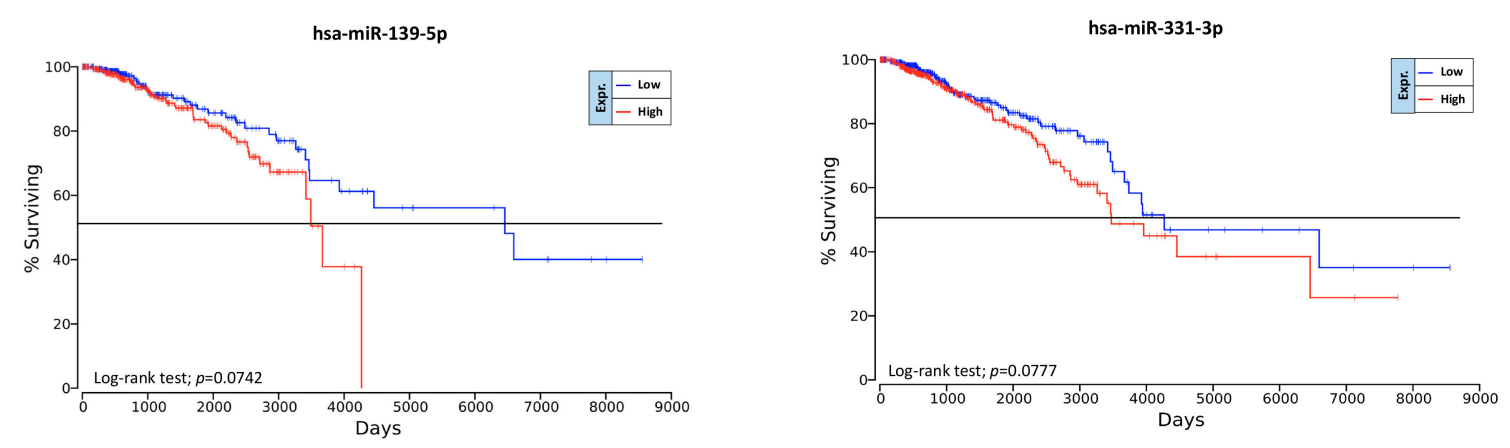

Figure 10. Prognostic value of exercise-modulated miRNAs according to OncoLnc.

\section{Discussion}

It is known that environmental and lifestyle factors influence the health status of individuals. It has been widely demonstrated that healthy diets and physical activity have beneficial effects in several pathological conditions including cancer $[55,56]$. Several studies have highlighted how some foods with a high glycemic index or inflammatory index are associated with chronic inflammation, and in turn, to a plethora of inflammatory-related diseases including cancer, diabetes, and cardiovascular diseases $[57,58]$. Indeed, nutrients can directly or indirectly modulate the molecular and physiological mechanisms responsible for cell proliferation, differentiation, and programmed cell death. Some foods including red meat, sugar, and saturated fats may induce inflammation and oxidative stress, thereby predisposing cells to genetic mutations [59]. In contrast, other foods and nutrients including vegetables, fruit, olive oil, and prebiotics may prevent cancer development, possibly due to their high content of vitamins, minerals, bioflavonoids, and isoflavones, which have antioxidant and hormone-modulating properties, dietary fiber, which can beneficially affect human microbiota, and unsaturated fats involved in reduced inflammation $[18,60,61]$. Although some molecular mechanisms have been elucidated by which diet and exercise prevent cancer development and progression, to date there are still no clinical cancer studies on the effect of integrative treatments on epigenetic modifications. Accordingly, the value of epigenetic alterations in predicting the efficacy of integrative treatments and the prognosis of patients is not established yet.

In this context, our research group proposed a cross-sectional randomized clinical trial, the "Vitamin D, Exercise, Diet and Breast Cancer" study (DEDiCa) (NCT02786875), aimed at reducing the risk of $\mathrm{BC}$ recurrence and at increasing the disease-free survival (DFS) in women with surgically resected $\mathrm{BC}$ through the administration of vitamin $\mathrm{D}$ and healthy lifestyle including mild/moderate physical activity and a low glycemic index Mediterranean diet. A secondary aim of the DEDiCa study was to investigate whether changes in lifestyle may induce changes in the expression levels of miRNAs associated with $\mathrm{BC}$ characteristics and with patient prognosis [37].

In line with the DEDiCa study, the aim of the present study was to computationally identify miRNAs strictly associated with $\mathrm{BC}$ progression and with diet and exercise interventions. For this purpose, a series of rigorous bioinformatic analyses were performed in order to select miRNAs with diagnostic and prognostic significance for BC and to identify the molecular pathways and genes modulated by diet and exercise.

As demonstrated in different studies, the availability of several cancer databases and of a huge amount of bioinformatic data on tumor molecular and clinical features has allowed for the accurate identification of useful biomarkers for the early diagnosis of malignant tumors or to predict the risk of cancer relapse [62-66]. 
In the present study, we proposed the integrated analysis of different miRNA expression profiling datasets obtained from the GEO DataSets related to BC patients with dietary or exercise interventions. This approach allowed for the collection of miRNA expression data related to more than $1000 \mathrm{BC}$ samples and healthy controls, which were merged with miRNA expression data obtained from more than 300 samples related to individuals undergoing diet or exercise interventions. The integration of different datasets and of a large number of samples allowed us to perform a more robust differential analysis compared to the analysis of single datasets. Furthermore, the selection of highly dysregulated miRNAs with concordant expression levels in the various datasets in which they were expressed allowed for the selection of those miRNAs actually involved in the development and progression of $\mathrm{BC}$ and certainly modulated by diet and exercise.

In particular, the integrated analysis of eight different BC miRNA microarray datasets allowed for the identification of a set of 49 upregulated and downregulated miRNAs in BC. Among these miRNAs, there were miRNAs already associated with the development of different tumors including those for BC. The most represented upregulated miRNAs were hsa-miR-106b-5p, hsa-miR-200a-3p, hsa-miR-21-5p, hsa-miR-141-3p, and hsa-miR-96-5p (over-expressed in seven out of eight datasets), while the most upregulated miRNAs (with higher log2FC value) were hsa-miR-182-5p, hsa-miR-183-5p, hsa-miR-7-5p, and the aforementioned hsa-miR-21-5p and hsa-miR-96-5p. Analogously, the most frequent downregulated miRNAs were hsa-miR-125b-5p and hsa-miR-99a-5p (downregulated in all eight analyzed datasets), hsa-miR-130a-3p, hsa-miR-205-5p, and hsa-miR-497-5p (seven out of eight datasets). Among the downregulated miRNAs, the higher log2FC were observed for hsa-miR-125b-5p, hsa-miR-139-5p, and hsa-miR-205-5p. The dysregulation of the identified miRNAs through the analysis of BC datasets was further confirmed by analyzing the miRNA expression data contained in TCGA BRCA database, thus corroborating the functional and diagnostic roles of these specific miRNAs in BC patients.

Of note, these dysregulated miRNAs are the result of the analysis of different datasets containing different molecular subtypes of $\mathrm{BC}$. Therefore, the analysis of a single miRNA may not give useful results for the effective detection of $B C$, while the concomitant evaluation of 49 miRNAs is representative and potentially predictive for the identification of all $\mathrm{BC}$ subtypes.

Regarding the upregulated miRNAs identified, several studies have already highlighted their oncogenic role. For example, increased levels of the miR-200 family were associated with a worse prognosis in several cancers including that of the breast [67]. Similarly, hsa-miR-21-5p is considered one of the main oncogenic miRNAs and its upregulation is observed in several cancers (e.g., breast, colorectal cancer, pancreatic, and non-small cell lung cancers) $[68,69]$. Furthermore, a specific axis involving the upregulated miRNA hsa-miR-96-5p, hsa-miR-182-5p, and hsa-miR-183-5p were identified in breast cancer and other tumors and these miRNAs are known to be responsible for abnormal cell proliferation and migration [70-72].

Regarding the downregulated miRNAs, hsa-miR-125b-5p is recognized as the most common downregulated miRNA in several cancers [73]. Other identified miRNAs like hsa-miR-139-5p, hsa-miR-205-5p, hsa-miR-486-5p, and hsa-miR-99a-5p have shown strong involvement in neoplastic transformations and some studies are trying to use these miRNAs for the development of novel therapeutic strategies in BC [74-77]. This evidence corroborates the real diagnostic and prognostic significance of these miRNAs in patients affected by BC. Therefore, the set of miRNAs we identified may be proposed as a panel of miRNAs for the monitoring of patients with BC. However, a single miRNA cannot be univocally considered as a tumor suppressor or oncomiR. Indeed, each miRNA is able to modulate the expression levels of different genes including both oncogenes and tumor suppressor genes. Therefore, the tumor-promoting or suppressive action of miRNAs is the result of a complex network of interactions that is established between different miRNAs and different genes involved in neoplastic transformation.

Although several studies have confirmed the specificity of selected miRNAs in BC, there are no concordant studies on the possible miRNA modulating effect of diet and exercise, especially for 
those miRNAs involved in BC. In this context, our results showed that 10 miRNAs were selectively modulated by exercise interventions and three by diet. Among those miRNAs dysregulated in BC, hsa-miR-7-5p, hsa-miR-139-5p, and hsa-miR-486-5p were also significantly modulated by exercise and diet. Therefore, the evaluation of these three miRNAs will be useful not only to predict the prognosis of patients, but also to evaluate the effectiveness of the integrative treatments as well as the adherence of patients to the dietary and exercise recommendations. Aside from these three miRNAs strongly associated with $\mathrm{BC}$, the other miRNAs modulated by diet and exercise may also play a fundamental role in BC; of these miRNAs, the upregulated miRNA hsa-miR-873-5p and the downregulated miRNA hsa-miR-199a-5p are involved in BC cells stemness and in tumor suppression, respectively [78,79].

The importance of the diet- and exercise-modulated miRNAs here identified for BC patients was further highlighted by the GEPIA and mirDIP analyses performed on the most important EMT genes. First, the GEPIA analysis showed that the expression levels of the epidermal marker CDH1 were upregulated in patients with $\mathrm{BC}$ compared to healthy individuals; in contrast, the mesenchymal marker (VIM) and the genes promoting the mesenchymal transition (SNAIL1/2, ZEB1/2, and TWIST1/2) were all downregulated in BC samples compared to the controls. These trends of expression are typical of all tumors originating from the epithelia. Subsequently, the mirDIP analysis revealed that both BC miRNAs and diet- and exercise-modulated miRNAs were able to strongly target the EMT genes whose dysregulation is associated with a worse prognosis in BC. In particular, both BC and diet- and exercisedifferentially expressed miRNAs were able to strongly interact with genes strongly responsible for mesenchymal transition including CTNNB1, ZEB1/2, and SNAIL2, suggesting that the fine regulation of such miRNAs mediated by dietary and exercise interventions may prevent EMT, thus reducing the risk of $\mathrm{BC}$ recurrence [80]. To the best of our knowledge, for the first time, the interactions between diet- and exercise-modulated miRNAs and genes potentially involved in $\mathrm{BC}$ were here investigated, thus suggesting a relationship between diet, exercise, $\mathrm{BC}$, and epigenetic mechanisms.

As a further demonstration of the effective involvement of both $\mathrm{BC}$ and diet- and exercise-modulated miRNAs in BC, the DIANA-mirPath analysis showed that the selected miRNAs were able to alter a total of 38 different cancer-related KEGG pathways ( 35 altered by BC miRNAs and five by diet- and exercise-modulated miRNAs; of these latter pathways, two were in common with the previous 35 pathways). Within these pathways, the most targeted genes were genes belonging to the Wnt/B-catenin pathway, the MAPKs pathway, and the PI3K/Akt pathway such as MAPK1, AKT family, PIK3 family, RAS/RAF genes, CCND1, EGFR, PTEN, etc. The alteration of all of these genes is known to be responsible for the development of $\mathrm{BC}$ [81]. In particular, the alteration of the PI3K/AKT pathway is recognized as a hallmark of $\mathrm{BC}$. Recent studies have highlighted how the modulation of some regulatory proteins in the PI3K/AKT pathway is mediated by various miRNAs $[82,83]$. In the same manner, several studies have demonstrated that the dysregulation of CCND1 is associated with cancer progression while the over-expression of EGFR and EGFR-ligands as well as the dysregulation of the RAS/RAF/ERK signaling pathway are associated with the acquisition of drug resistance associated with cancer progression [84-86].

The involvement of these miRNA-targeted genes in BC was not only predicted, but also validated through the use of STRING and GO Panther enrichment analyses. These analyses thus confirmed that these genes are strongly involved in the breast cancer KEGG pathways (hsa05224), affecting different biological process and molecular functions as well as all cellular levels from the extracellular portion with the modulation of signal molecules (WNT and FGF families) up to the nucleus with the modulation of different transcription factors (E2F family) [87].

Finally, other important findings derived from the OncoLnc analysis allowed for the identification of miRNAs predictive of patient outcome.

Although the OncoLnc analysis performed on diet- and exercise- modulated miRNAs did not produce statistically significant results, the same analysis conducted on those 49 miRNAs closely associated with the development of $B C$ revealed five miRNAs predicting overall survival (i.e., the downregulated miRNAs hsa-miR-484, hsa-miR-185-5p, hsa-miR-340-5p, and hsa-miR-146a-5p 
and the upregulated miRNA hsa-miR-195-5p). Several researchers have attempted to independently validate the prognostic significance of these miRNAs, albeit with controversial results [88-92]. However, here we suggest a novel prognostic strategy for the management of $\mathrm{BC}$ based on the evaluation of multiple miRNAs instead of single miRNAs that alone are not predictive of $\mathrm{BC}$ recurrence or patient survival.

Interestingly, although not statistically significant, the hsa-miR-139-5p and hsa-miR-331-3p downregulated by exercise may be good indicators of the efficacy of the integrative intervention and of patient prognosis as demonstrated by two independent studies $[93,94]$.

Overall, the bioinformatic analyses described above allowed for the identification of specific miRNAs able to predict the risk of BC recurrence, the efficacy of the diet and exercise treatments, and patient prognosis. These findings, together with the new diagnostic approaches based on liquid biopsy samples, circulating tumor DNA (ctDNA) [95], and high-sensitive techniques like droplet digital PCR (ddPCR) [96-99], will allow for the effective validation of the prognostic significance of selected miRNAs in liquid biopsy samples obtained from BC patients treated with integrative interventions in order to improve current follow-up strategies as well as their quality of life.

However, as previously stated, the identification of promising non-invasive biomarkers cannot be based on the analysis of a single miRNA, but it is necessary to carry out the integrated analysis of a panel of miRNAs or different circulating markers (including miRNAs, proteins, and genetic or expression markers) to increase the specificity of liquid biopsy-based diagnostic strategies. In addition, it is important to note that often inconsistency exists between the expression levels of miRNA in tissue and liquid biopsy samples [100]. Therefore, the analysis of liquid biopsy samples may need to be confirmed by the analysis of miRNA expression in tissue specimens.

\section{Materials and Methods}

\section{1. microRNA Expression Profiling Dataset Selection}

For the identification of miRNAs strictly involved in the development and progression of BC and actively modulated by diet and exercise, the publicly available GEO DataSets database was used. Three different searches were performed in order to select microarray miRNA expression profiling datasets related to $\mathrm{BC}$, dietary, and exercise interventions, respectively. For this purpose, three independent advanced searches were performed as previously described [101]. In particular, for the selection of microarray datasets containing data about miRNA expression levels in BC, the following search terms were used: "((breast cancer) AND 'non coding rna profiling by array' [DataSet Type]) AND ‘Homo sapiens' [porgn:_txid9606]".

For the selection of microarray expression profiling datasets related to dietary and exercise interventions, the following two search strings were used: "((diet) AND 'non coding rna profiling by array' [DataSet Type]) AND 'Homo sapiens' [porgn:_txid9606]" and "((Exercise) AND 'non coding rna profiling by array' [DataSet Type]) AND 'Homo sapiens' [porgn:_txid9606]".

All three searches were performed on the relevant datasets available up to March 2020.

Regarding the datasets selected for diet and exercise, the only inclusion criterion adopted was datasets containing miRNA expression levels of treated and untreated human samples, thus discarding all datasets obtained from animal models, cell lines, or other in vitro experiments.

Instead, regarding the selection of BC miRNA datasets, the advanced search allowed for the identification of a list of all BC datasets containing miRNA expression levels. The inclusion and exclusion criteria for these datasets were as follows:

Inclusion criteria: (i) datasets containing miRNA expression levels of $\mathrm{BC}$ tissues excluding datasets containing serum or plasma samples; (ii) datasets reporting miRNAs expression levels of both tumor and normal tissue samples; and (iii) datasets containing miRNA expression data of at least 10 tumor samples and 10 controls. 
Exclusion criteria: (i) datasets containing exclusively tumor samples; (ii) datasets containing miRNAs expression levels of animal models, cell lines or other in vitro experiments; and (iii) datasets containing miRNAs expression levels detected in serum/plasma samples.

In particular, data derived from liquid biopsy samples were discarded in order to select only datasets containing tissue samples with miRNA expression levels strictly associated with the tumor mass.

Finally, the miRNA expression data contained in the "miRNA mature strand expression RNAseq" dataset of the Cancer Genome Atlas Breast Cancer (TCGA BRCA) database were analyzed to further confirm the miRNA expression results obtained from GEO DataSets microarray platforms.

\subsection{Differential Analysis between Groups and microRNA Annotation}

Regarding the $\mathrm{BC}$ datasets, differential analyses were performed between the tumor samples and normal breast tissues, while for the diet and exercise datasets, the differential analyses of miRNAs expression levels were performed between dietary and exercise treated and untreated samples.

In particular, the data matrices were obtained from each GSE dataset and samples were stratified into two distinctive groups (Tumors vs. Normal; Diet vs. No Diet, Exercise vs. No Exercise). Before differential analysis, the miRNAs of each dataset were annotated using the latest version of miRBase nomenclature (V.22.) (http://www.mirbase.org/), thus converting the sequence or the miRNA ID (MIMAT00 code) of each miRNA in the following nomenclature "hsa-miR-". The differential analyses between groups were subsequently performed by using the GEO2R software publicly available on GEO DataSets. The results of the differential analyses were expressed as base- 2 logarithm of Fold Change $(\log 2 \mathrm{FC})$ in order to normalize the variability of results obtained from different microarray technologies.

miRNAs with $\log 2 \mathrm{FC}$ with a statistical significance of $p<0.01$ (for $\mathrm{BC}$ datasets) or $p<0.05$ (for diet and exercise datasets) were selected as significantly deregulated miRNAs.

\subsection{Identification of microRNAs Involved in Breast Cancer and Effectively Modulated by Diet and Exercise}

The lists of differentially expressed miRNAs obtained for each BC dataset were subsequently merged by using the publicly available Venn Diagrams of the Bioinformatics \& Evolutionary Genomics (BEG) tool (http://bioinformatics.psb.ugent.be/webtools/Venn/). The same analysis was performed for the diet and exercise datasets.

After data merging, among all the dysregulated miRNAs in the BC, diet, and exercise datasets, only those highly upregulated or downregulated and with concordant expression levels in more than $50 \%$ of the analyzed datasets were selected.

For each miRNA, the log2FC was reported indicating with red boxes the over-expressed miRNAs and with blue boxes the downregulated ones.

\subsection{Interaction between Selected microRNAs and Epithelial-Mesenchymal Transition (EMT) Genes}

After miRNA selection, the basal expression levels of EMT genes including CTNNB1, TWIST1/2, SNAIL1/2, ZEB1/2, VIM, CDH1 (E-Cad), and CDH2 (N-Cad) were analyzed in the BC samples and in healthy controls. For this purpose, the GEPIA software (http://gepia.cancer-pku.cn/index.html), capable of deriving and processing the RNA sequencing expression data of 1085 breast cancer samples and 291 normal breast tissues contained in the TCGA Breast Invasive Carcinoma and GTEx datasets, was used [102].

Subsequently, the interaction levels between the computationally identified BC miRNAs and genes responsible for EMT were established by using the bioinformatic tool microRNA Data Integration Portal (mirDIP-Version 4.1.11.1, Database version 4.1.0.3, September 2018) (http://ophid.utoronto.ca/mirDIP). In particular, mirDIP software allowed for the integration of the human RNA-gene target predictions contained in 30 different miRNA prediction databases, thus obtaining more robust data about the interaction levels between miRNAs and gene targets and avoiding database-specific bias [103]. 
The mirDIP analysis was performed for the aforementioned EMT genes: CTNNB1, TWIST1/2, SNAIL1/2, ZEB1/2, VIM, CDH1 (E-Cad) and CDH2 (N-Cad).

\section{5. microRNA Pathway Prediction Analysis}

For the diet- and exercise-modulated miRNAs previously identified, a pathway prediction analysis was performed to investigate the role of such miRNAs in the modulation of molecular and signal transduction pathways known to be involved in tumor progression. For this purpose, the computational prediction tool DIANA-mirPath (v.3) was used as previously described [104]. Briefly, DIANA-mirPath is able to identify the molecular pathways significantly modulated by a list of miRNAs predicting the targeted $3^{\prime}$-UTR gene regions by consulting the experimentally validated miRNA interactions obtained from the DIANA-TarBase v7.0 database [105]. These interactions (predicted and/or validated) were subsequently combined with sophisticated merging and meta-analysis algorithms by DIANA-mirPath, giving as a result the genes and pathways targeted by a specific miRNA and the statistical significance of this interaction.

\section{6. miRNA-Targeted Genes Interaction and Gene Ontology (GO)}

To better understand the functional effects of exercise- and diet- modulated miRNAs, STRING: Functional protein association networks' (https://string-db.org/) software was used to establish the interaction network of the genes identified through DIANA-mirPath analysis [106]. For both exerciseand diet- modulated genes, the involvement within the breast cancer KEGG pathway (hsa05224) was highlighted.

For the genes identified through DIANA-mirPath, the software GO Panther (GO Panther v.14.0-http://pantherdb.org/) [107] was used to perform GO analysis. The DIANA-mirPath-selected genes were classified according to their Molecular Function (MC), Biological Process (BP), and Cellular Component (CC).

\subsection{Prognostic Significance of Computationally Selected microRNAs}

In order to determine the prognostic significance of the computationally selected miRNAs obtained from the BC, diet, and exercise datasets, the bioinformatics tool OncoLnc (http://www.oncolnc.org/) was used [108]. In particular, OncoLnc is able to calculate Kaplan-Meier curves by analyzing the miRNA expression and survival data derived from TCGA BRCA datasets. The Kaplan-Meier curves were obtained following the instruction provided by the developers of the software, thus comparing the miRNA expression levels and survival data of the bottom quartile samples and top quartile samples. Overall survival (OS) curves were reported only when the log-rank $p$-value was $p<0.05$.

\subsection{Statistical Analyses}

The $\log 2 \mathrm{FC}$ values of the computationally selected miRNAs were already normalized by the GEO2R software. As stated before, for the BC datasets, miRNAs with a $p$-value of $p<0.01$ were selected, while for the diet and exercise datasets, miRNAs with a $p$-value of $p<0.05$ were selected. With regard to the GO and pathway prediction analyses, STRING, GO Panther, and DIANA-mirPath automatically perform proper statistical tests, providing statistically significant data expressed as $p$-values. Finally, for the Kaplan-Meier analysis, only overall survival curves with a log-rank $p$-value $p<0.05$ were selected.

\section{Conclusions}

The integration of different miRNA expression microarray datasets and the use of several bioinformatics prediction tools has allowed for the identification of miRNAs strictly involved in BC. Among these, the miRNAs hsa-miR-182-5p, hsa-miR-183-5p, hsa-miR-200 family, hsa-miR-21-5p, hsa-miR-7-5p, hsa-miR-96-5p, hsa-miR-125b-5p, hsa-miR-139-5p, hsa-miR-497-5p, hsa-miR-99a-5p, 
and hsa-miR-486-5p were altered in BC and modulated by diet and exercise interventions while the miRNAs hsa-miR-484, hsa-miR-185-5p, hsa-miR-340-5p, hsa-miR-146a-5p, hsa-miR-195-5p, hsa-miR-139-5p, and hsa-miR-331-3p were specific for the prediction of the survival of patients. These data suggest that diet and exercise exert a double protective role in cancer through the modulation of epigenetic factors and the well-documented positive regulation of gene expression.

The in silico results here obtained represent the starting point for the in vivo validation that will be performed in liquid biopsy samples collected from BC patients. In particular, future validation studies will benefit from our clinical trial DEDiCa, where the expression levels of miRNAs identified in the current in silico study will be analyzed in liquid biopsy samples obtained from BC patients treated with a lifestyle treatment by using specific ddPCR probes for the selected miRNAs. The miRNA expression results will be further compared with the clinical-pathological features of patients and the data obtained from food and physical activity diaries in order to establish the effectiveness of DEDiCa treatment in reducing the risk of $\mathrm{BC}$ recurrence and in improving the general health and quality of life of patients.

Author Contributions: Conceptualization, L.F., M.L. and L.S.A.A.; Formal analysis, L.F. and M.G.; Investigation, L.F. and E.C.; Supervision, E.C. and M.L.; Writing-original draft, L.F; Writing-review \& editing, L.F., M.G., E.C., L.S.A.A. and M.L. All authors have read and agreed to the published version of the manuscript.

Funding: This research was funded by a grant from the Italian Ministry of Health (grant no. PE-2013-02358099).

Acknowledgments: The authors would like to thank the "Lega Italiana per la Lotta contro i Tumori (LILT)" for its support. The authors would like also to thank the support kindly provided by the researchers of the Research Center for Prevention, Diagnosis, and Treatment of Cancer, University of Catania, Catania.

Conflicts of Interest: The authors declare no conflict of interest.

\section{References}

1. Bray, F.; Ferlay, J.; Soerjomataram, I.; Siegel, R.L.; Torre, L.A.; Jemal, A. Global cancer statistics 2018: GLOBOCAN estimates of incidence and mortality worldwide for 36 cancers in 185 countries. CA Cancer J. Clin. 2018, 68, 394-424. [CrossRef]

2. Falzone, L.; Salomone, S.; Libra, M. Evolution of Cancer Pharmacological Treatments at the Turn of the Third Millennium. Front. Pharmacol. 2018, 9, 1300. [CrossRef] [PubMed]

3. Hendrick, R.E.; Baker, J.A.; Helvie, M.A. Breast cancer deaths averted over 3 decades. Cancer 2019, 125, 1482-1488. [CrossRef] [PubMed]

4. Christofi, T.; Baritaki, S.; Falzone, L.; Libra, M.; Zaravinos, A. Current Perspectives in Cancer Immunotherapy. Cancers 2019, 11, 1472. [CrossRef] [PubMed]

5. Carayol, M.; Ninot, G.; Senesse, P.; Bleuse, J.P.; Gourgou, S.; Sancho-Garnier, H.; Sari, C.; Romieu, I.; Romieu, G.; Jacot, W. Short- and long-term impact of adapted physical activity and diet counseling during adjuvant breast cancer therapy: The "APAD1" randomized controlled trial. BMC Cancer 2019, 19, 737. [CrossRef] [PubMed]

6. Lyman, G.H.; Greenlee, H.; Bohlke, K.; Bao, T.; DeMichele, A.M.; Deng, G.E.; Fouladbakhsh, J.M.; Gil, B.; Hershman, D.L.; Mansfield, S.; et al. Integrative Therapies During and After Breast Cancer Treatment: ASCO Endorsement of the SIO Clinical Practice Guideline. J. Clin. Oncol. 2018, 36, 2647-2655. [CrossRef] [PubMed]

7. Hack, C.C.; Hackl, J.; Hüttner, N.B.M.; Langemann, H.; Schwitulla, J.; Dietzel-Drentwett, S.; Fasching, P.A.; Beckmann, M.W.; Theuser, A.K. Self-reported Improvement in Side Effects and Quality of Life With Integrative Medicine in Breast Cancer Patients. Integr. Cancer Ther. 2018, 17, 941-951. [CrossRef] [PubMed]

8. Sudhakaran, M.; Sardesai, S.; Doseff, A.I. Flavonoids: New Frontier for Immuno-Regulation and Breast Cancer Control. Antioxidants 2019, 8, 103. [CrossRef]

9. Lopes, C.M.; Dourado, A.; Oliveira, R. Phytotherapy and Nutritional Supplements on Breast Cancer. Biomed. Res. Int. 2017, 2017, 7207983. [CrossRef]

10. Mendoza, L. Potential effect of probiotics in the treatment of breast cancer. Oncol. Rev. 2019, 13, 422. [CrossRef] 
11. Vivarelli, S.; Salemi, R.; Candido, S.; Falzone, L.; Santagati, M.; Stefani, S.; Torino, F.; Banna, G.L.; Tonini, G.; Libra, M. Gut Microbiota and Cancer: From Pathogenesis to Therapy. Cancers 2019, 11, 38. [CrossRef] [PubMed]

12. Lopez, G.; Eddy, C.; Liu, W.; Li, Y.; Chen, M.; Bruera, E.; Cohen, L. Physical Therapist-Led Exercise Assessment and Counseling in Integrative Cancer Care: Effects on Patient Self-reported Symptoms and Quality of Life. Integr. Cancer Ther. 2019, 18, 1534735419832360. [CrossRef] [PubMed]

13. Browall, M.; Mijwel, S.; Rundqvist, H.; Wengström, Y. Physical Activity During and After Adjuvant Treatment for Breast Cancer: An Integrative Review of Women's Experiences. Integr. Cancer Ther. 2018, 17, 16-30. [CrossRef] [PubMed]

14. De Cicco, P.; Catani, M.V.; Gasperi, V.; Sibilano, M.; Quaglietta, M.; Savini, I. Nutrition and Breast Cancer: A Literature Review on Prevention, Treatment and Recurrence. Nutrients 2019, 11, 1514. [CrossRef] [PubMed]

15. Zimta, A.A.; Tigu, A.B.; Muntean, M.; Cenariu, D.; Slaby, O.; Berindan-Neagoe, I. Molecular Links between Central Obesity and Breast Cancer. Int. J. Mol. Sci. 2019, 20, 5364. [CrossRef] [PubMed]

16. Kotsopoulos, J. Menopausal hormones: Definitive evidence for breast cancer. Lancet 2019, 394, 1116-1118. [CrossRef]

17. Key, T.J.; Balkwill, A.; Bradbury, K.E.; Reeves, G.K.; Kuan, A.S.; Simpson, R.F.; Green, J.; Beral, V. Foods, macronutrients and breast cancer risk in postmenopausal women: A large UK cohort. Int. J. Epidemiol. 2019, 48, 489-500. [CrossRef]

18. Banna, G.L.; Torino, F.; Marletta, F.; Santagati, M.; Salemi, R.; Cannarozzo, E.; Falzone, L.; Ferraù, F.; Libra, M. Lactobacillus rhamnosus GG: An Overview to Explore the Rationale of Its Use in Cancer. Front. Pharmacol. 2017, 8, 603. [CrossRef]

19. Ferroni, P.; Riondino, S.; Buonomo, O.; Palmirotta, R.; Guadagni, F.; Roselli, M. Type 2 Diabetes and Breast Cancer: The Interplay between Impaired Glucose Metabolism and Oxidant Stress. Oxid. Med. Cell Longev. 2015, 2015, 183928. [CrossRef]

20. Alves, B.C.; Silva, T.R.; Spritzer, P.M. Sedentary Lifestyle and High-Carbohydrate Intake are Associated with Low-Grade Chronic Inflammation in Post-Menopause: A Cross-sectional Study. Rev. Bras. Ginecol. Obs. 2016, 38, 317-324. [CrossRef]

21. Jang, H.; Chung, M.S.; Kang, S.S.; Park, Y. Association between the Dietary Inflammatory Index and Risk for Cancer Recurrence and Mortality among Patients with Breast Cancer. Nutrients 2018, 10, 1095. [CrossRef] [PubMed]

22. Romieu, I.; Ferrari, P.; Rinaldi, S.; Slimani, N.; Jenab, M.; Olsen, A.; Tjonneland, A.; Overvad, K.; Boutron-Ruault, M.C.; Lajous, M.; et al. Dietary glycemic index and glycemic load and breast cancer risk in the European Prospective Investigation into Cancer and Nutrition (EPIC). Am. J. Clin. Nutr. 2012, 96, 345-355. [CrossRef] [PubMed]

23. Bodén, S.; Myte, R.; Wennberg, M.; Harlid, S.; Johansson, I.; Shivappa, N.; Hébert, J.R.; Van Guelpen, B.; Nilsson, L.M. The inflammatory potential of diet in determining cancer risk; A prospective investigation of two dietary pattern scores. PLoS ONE 2019, 14, e0214551. [CrossRef] [PubMed]

24. Zitvogel, L.; Pietrocola, F.; Kroemer, G. Nutrition, inflammation and cancer. Nat. Immunol. 2017, 18, 843-850. [CrossRef] [PubMed]

25. Ultimo, S.; Zauli, G.; Martelli, A.M.; Vitale, M.; McCubrey, J.A.; Capitani, S.; Neri, L.M. Influence of physical exercise on microRNAs in skeletal muscle regeneration, aging and diseases. Oncotarget 2018, 9, 17220-17237. [CrossRef] [PubMed]

26. Quintanilha, B.J.; Reis, B.Z.; Duarte, G.B.S.; Cozzolino, S.M.F.; Rogero, M.M. Nutrimiromics: Role of microRNAs and Nutrition in Modulating Inflammation and Chronic Diseases. Nutrients 2017, 9, 1168. [CrossRef]

27. Giardina, S.; Hernández-Alonso, P.; Díaz-López, A.; Salas-Huetos, A.; Salas-Salvadó, J.; Bulló, M. Changes in circulating miRNAs in healthy overweight and obese subjects: Effect of diet composition and weight loss. Clin. Nutr. 2019, 38, 438-443. [CrossRef]

28. Falzone, L.; Salemi, R.; Travali, S.; Scalisi, A.; McCubrey, J.A.; Candido, S.; Libra, M. MMP-9 overexpression is associated with intragenic hypermethylation of MMP9 gene in melanoma. Aging 2016, 8, 933-944. [CrossRef]

29. Humphries, B.; Wang, Z.; Yang, C. MicroRNA Regulation of Epigenetic Modifiers in Breast Cancer. Cancers 2019, 11, 897. [CrossRef] 
30. Gillman, A.S.; Gardiner, C.K.; Koljack, C.E.; Bryan, A.D. Body mass index, diet, and exercise: Testing possible linkages to breast cancer risk via DNA methylation. Breast Cancer Res. Treat. 2018, 168, 241-248. [CrossRef]

31. Toledo, E.; Salas-Salvadó, J.; Donat-Vargas, C.; Buil-Cosiales, P.; Estruch, R.; Ros, E.; Corella, D.; Fitó, M.; Hu, F.B.; Arós, F.; et al. Mediterranean Diet and Invasive Breast Cancer Risk Among Women at High Cardiovascular Risk in the PREDIMED Trial: A Randomized Clinical Trial. JAMA Intern. Med. 2015, 175, 1752-1760. [CrossRef] [PubMed]

32. Shapira, N. The potential contribution of dietary factors to breast cancer prevention. Eur. J. Cancer Prev. 2017, 26, 385-395. [CrossRef] [PubMed]

33. Wirtz, P.; Baumann, F.T. Physical Activity, Exercise and Breast Cancer-What Is the Evidence for Rehabilitation, Aftercare, and Survival? A Review. Breast Care 2018, 13, 93-101. [CrossRef] [PubMed]

34. Adams, B.D.; Arem, H.; Hubal, M.J.; Cartmel, B.; Li, F.; Harrigan, M.; Sanft, T.; Cheng, C.J.; Pusztai, L.; Irwin, M.L. Exercise and weight loss interventions and miRNA expression in women with breast cancer. Breast Cancer Res. Treat. 2018, 170, 55-67. [CrossRef] [PubMed]

35. Ntanasis-Stathopoulos, J.; Tzanninis, J.G.; Philippou, A.; Koutsilieris, M. Epigenetic regulation on gene expression induced by physical exercise. J. Musculoskelet. Neuronal Interact. 2013, 13, 133-146.

36. Lope, V.; Martín, M.; Castelló, A.; Ruiz, A.; Casas, A.M.; Baena-Cañada, J.M.; Antolín, S.; Ramos-Vázquez, M.; García-Sáenz, J.Á.; Muñoz, M.; et al. Overeating, caloric restriction and breast cancer risk by pathologic subtype: The EPIGEICAM study. Sci. Rep. 2019, 9, 3904. [CrossRef]

37. Augustin, L.S.; Libra, M.; Crispo, A.; Grimaldi, M.; De Laurentiis, M.; Rinaldo, M.; D'Aiuto, M.; Catalano, F.; Banna, G.; Ferrau', F.; et al. Low glycemic index diet, exercise and vitamin D to reduce breast cancer recurrence (DEDiCa): Design of a clinical trial. BMC Cancer 2017, 17, 69. [CrossRef]

38. Zhao, X.G.; Hu, J.Y.; Tang, J.; Yi, W.; Zhang, M.Y.; Deng, R.; Mai, S.J.; Weng, N.Q.; Wang, R.Q.; Liu, J.; et al. miR-665 expression predicts poor survival and promotes tumor metastasis by targeting NR4A3 in breast cancer. Cell Death Dis. 2019, 10, 479. [CrossRef]

39. Hironaka-Mitsuhashi, A.; Matsuzaki, J.; Takahashi, R.U.; Yoshida, M.; Nezu, Y.; Yamamoto, Y.; Shiino, S.; Kinoshita, T.; Ushijima, T.; Hiraoka, N.; et al. A tissue microRNA signature that predicts the prognosis of breast cancer in young women. PLoS ONE 2017, 12, e0187638. [CrossRef]

40. Matamala, N.; Vargas, M.T.; González-Cámpora, R.; Miñambres, R.; Arias, J.I.; Menéndez, P.; Andrés-León, E.; Gómez-López, G.; Yanowsky, K.; Calvete-Candenas, J.; et al. Tumor microRNA expression profiling identifies circulating microRNAs for early breast cancer detection. Clin. Chem. 2015, 61, 1098-1106. [CrossRef]

41. Avery-Kiejda, K.A.; Braye, S.G.; Mathe, A.; Forbes, J.F.; Scott, R.J. Decreased expression of key tumour suppressor microRNAs is associated with lymph node metastases in triple negative breast cancer. BMC Cancer 2014, 14, 51. [CrossRef] [PubMed]

42. Tanić, M.; Yanowski, K.; Andrés, E.; Gómez-López, G.; Socorro, M.R.; Pisano, D.G.; Martinez-Delgado, B.; Benítez, J. miRNA expression profiling of formalin-fixed paraffin-embedded (FFPE) hereditary breast tumors. Genom. Data 2014, 3, 75-79. [CrossRef]

43. Lee, C.H.; Kuo, W.H.; Lin, C.C.; Oyang, Y.J.; Huang, H.C.; Juan, H.F. MicroRNA-regulated protein-protein interaction networks and their functions in breast cancer. Int. J. Mol. Sci. 2013, 14, 11560-11606. [CrossRef] [PubMed]

44. Cimino, D.; De Pittà, C.; Orso, F.; Zampini, M.; Casara, S.; Penna, E.; Quaglino, E.; Forni, M.; Damasco, C.; Pinatel, E.; et al. miR148b is a major coordinator of breast cancer progression in a relapse-associated microRNA signature by targeting ITGA5, ROCK1, PIK3CA, NRAS, and CSF1. FASEB J. 2013, 27, 1223-1235. [CrossRef]

45. Biagioni, F.; Bossel Ben-Moshe, N.; Fontemaggi, G.; Canu, V.; Mori, F.; Antoniani, B.; Di Benedetto, A.; Santoro, R.; Germoni, S.; De Angelis, F.; et al. miR-10b*, a master inhibitor of the cell cycle, is down-regulated in human breast tumours. EMBO Mol. Med. 2012, 4, 1214-1229. [CrossRef] [PubMed]

46. McCann, S.E.; Liu, S.; Wang, D.; Shen, J.; Hu, Q.; Hong, C.C.; Newman, V.A.; Zhao, H. Reduction of dietary glycaemic load modifies the expression of microRNA potentially associated with energy balance and cancer pathways in pre-menopausal women. Br. J. Nutr. 2013, 109, 585-592. [CrossRef]

47. Kristensen, M.M.; Davidsen, P.K.; Vigelsø, A.; Hansen, C.N.; Jensen, L.J.; Jessen, N.; Bruun, J.M.; Dela, F.; Helge, J.W. miRNAs in human subcutaneous adipose tissue: Effects of weight loss induced by hypocaloric diet and exercise. Obesity 2017, 25, 572-580. [CrossRef] 
48. D'Amore, S.; Vacca, M.; Cariello, M.; Graziano, G.; D’Orazio, A.; Salvia, R.; Sasso, R.C.; Sabbà, C.; Palasciano, G.; Moschetta, A. Genes and miRNA expression signatures in peripheral blood mononuclear cells in healthy subjects and patients with metabolic syndrome after acute intake of extra virgin olive oil. Biochim. Biophys. Acta 2016, 1861, 1671-1680. [CrossRef]

49. Kern, F.; Ludwig, N.; Backes, C.; Maldener, E.; Fehlmann, T.; Suleymanov, A.; Meese, E.; Hecksteden, A.; Keller, A.; Meyer, T. Systematic Assessment of Blood-Borne MicroRNAs Highlights Molecular Profiles of Endurance Sport and Carbohydrate Uptake. Cells 2019, 8, 1045. [CrossRef]

50. Chilton, W.L.; Marques, F.Z.; West, J.; Kannourakis, G.; Berzins, S.P.; O’Brien, B.J.; Charchar, F.J. Acute exercise leads to regulation of telomere-associated genes and microRNA expression in immune cells. PLOS ONE 2014, 9, e92088. [CrossRef]

51. Radom-Aizik, S.; Zaldivar, F.P., Jr.; Haddad, F.; Cooper, D.M. Impact of brief exercise on circulating monocyte gene and microRNA expression: Implications for atherosclerotic vascular disease. Brain Behav. Immun. 2014, 39, 121-129. [CrossRef] [PubMed]

52. Radom-Aizik, S.; Zaldivar, F.; Haddad, F.; Cooper, D.M. Impact of brief exercise on peripheral blood NK cell gene and microRNA expression in young adults. J. Appl. Physiol. 2013, 114, 628-636. [CrossRef] [PubMed]

53. Radom-Aizik, S.; Zaldivar, F., Jr.; Leu, S.Y.; Adams, G.R.; Oliver, S.; Cooper, D.M. Effects of exercise on microRNA expression in young males peripheral blood mononuclear cells. Version 2. Clin. Transl. Sci. 2012, 5, 32-38. [CrossRef] [PubMed]

54. Radom-Aizik, S.; Zaldivar, F., Jr.; Oliver, S.; Galassetti, P.; Cooper, D.M. Evidence for microRNA involvement in exercise-associated neutrophil gene expression changes. J. Appl. Physiol. 2010, 109, 252-261. [CrossRef] [PubMed]

55. Witard, O.C.; Ball, D. The interaction between nutrition and exercise for promoting health and performance. Proc. Nutr. Soc. 2018, 77, 1-3. [CrossRef] [PubMed]

56. Baguley, B.J.; Bolam, K.A.; Wright, O.R.L.; Skinner, T.L. The Effect of Nutrition Therapy and Exercise on Cancer-Related Fatigue and Quality of Life in Men with Prostate Cancer: A Systematic Review. Nutrients 2017, 9, 1003. [CrossRef]

57. Kouvari, M.; Panagiotakos, D.B.; Naumovski, N.; Chrysohoou, C.; Georgousopoulou, E.N.; Yannakoulia, M.; Tousoulis, D.; Pitsavos, C.; ATTICA study Investigators. Dietary anti-inflammatory index, metabolic syndrome and transition in metabolic status; a gender-specific analysis of ATTICA prospective study. Diabetes Res. Clin. Pract. 2020, 161, 108031. [CrossRef]

58. Zabłocka-Słowińska, K.A.; Skórska, K.; Płaczkowska, S.; Prescha, A.; Pawełczyk, K.; Kosacka, M.; Porębska, I.; Grajeta, H. The relationships between glycemic index and glycemic load of diets and nutritional status and antioxidant/oxidant status in the serum of patients with lung cancer. Adv. Clin. Exp. Med. 2019, 28, 1027-1036. [CrossRef]

59. Saha, S.K.; Lee, S.B.; Won, J.; Choi, H.Y.; Kim, K.; Yang, G.M.; Dayem, A.A.; Cho, S.G. Correlation between Oxidative Stress, Nutrition, and Cancer Initiation. Int. J. Mol. Sci. 2017, 18, 1544. [CrossRef]

60. Mentella, M.C.; Scaldaferri, F.; Ricci, C.; Gasbarrini, A.; Miggiano, G.A.D. Cancer and Mediterranean Diet: A Review. Nutrients 2019, 11, 2059. [CrossRef]

61. Hardman, W.E. Diet components can suppress inflammation and reduce cancer risk. Nutr. Res. Pract. 2014, 8, 233-240. [CrossRef] [PubMed]

62. Candido, S.; Lupo, G.; Pennisi, M.; Basile, M.S.; Anfuso, C.D.; Petralia, M.C.; Gattuso, G.; Vivarelli, S.; Spandidos, D.A.; Libra, M.; et al. The analysis of miRNA expression profiling datasets reveals inverse microRNA patterns in glioblastoma and Alzheimer's disease. Oncol. Rep. 2019, 42, 911-922. [CrossRef] [PubMed]

63. Falzone, L.; Lupo, G.; La Rosa, G.R.M.; Crimi, S.; Anfuso, C.D.; Salemi, R.; Rapisarda, E.; Libra, M.; Candido, S. Identification of Novel MicroRNAs and Their Diagnostic and Prognostic Significance in Oral Cancer. Cancers 2019, 11, 610. [CrossRef] [PubMed]

64. Miller, M.D.; Salinas, E.A.; Newtson, A.M.; Sharma, D.; Keeney, M.E.; Warrier, A.; Smith, B.J.; Bender, D.P.; Goodheart, M.J.; Thiel, K.W.; et al. An integrated prediction model of recurrence in endometrial endometrioid cancers. Cancer Manag. Res. 2019, 11, 5301-5315. [CrossRef] [PubMed] 
65. Falzone, L.; Candido, S.; Salemi, R.; Basile, M.S.; Scalisi, A.; McCubrey, J.A.; Torino, F.; Signorelli, S.S.; Montella, M.; Libra, M. Computational identification of microRNAs associated to both epithelial to mesenchymal transition and NGAL/MMP-9 pathways in bladder cancer. Oncotarget 2016, 7, 72758-72766. [CrossRef]

66. Hafsi, S.; Candido, S.; Maestro, R.; Falzone, L.; Soua, Z.; Bonavida, B.; Spandidos, D.A.; Libra, M. Correlation between the overexpression of Yin Yang 1 and the expression levels of miRNAs in Burkitt's lymphoma: A computational study. Oncol. Lett. 2016, 11, 1021-1025. [CrossRef]

67. Huang, G.L.; Sun, J.; Lu, Y.; Liu, Y.; Cao, H.; Zhang, H.; Calin, G.A. MiR-200 family and cancer: From a meta-analysis view. Mol. Asp. Med. 2019, 70, 57-71. [CrossRef]

68. Wang, H.; Tan, Z.; Hu, H.; Liu, H.; Wu, T.; Zheng, C.; Wang, X.; Luo, Z.; Wang, J.; Liu, S.; et al. microRNA-21 promotes breast cancer proliferation and metastasis by targeting LZTFL1. BMC Cancer 2019, 19, 738. [CrossRef]

69. Feng, Y.H.; Tsao, C.J. Emerging role of microRNA-21 in cancer. Biomed. Rep. 2016, 5, 395-402. [CrossRef]

70. Coker-Gurkan, A.; Bulut, D.; Genc, R.; Arisan, E.D.; Obakan-Yerlikaya, P.; Palavan-Unsal, N. Curcumin prevented human autocrine growth hormone (GH) signaling mediated NF- $k$ B activation and miR-183-96-182 cluster stimulated epithelial mesenchymal transition in T47D breast cancer cells. Mol. Biol. Rep. 2019, 46, 355-369. [CrossRef]

71. Zhang, Q.; Ren, W.; Huang, B.; Yi, L.; Zhu, H. MicroRNA-183/182/96 cooperatively regulates the proliferation of colon cancer cells. Mol. Med. Rep. 2015, 12, 668-674. [CrossRef] [PubMed]

72. Li, P.; Sheng, C.; Huang, L.; Zhang, H.; Huang, L.; Cheng, Z.; Zhu, Q. MiR-183/-96/-182 cluster is up-regulated in most breast cancers and increases cell proliferation and migration. Breast Cancer Res. 2014, 16, 473. [CrossRef] [PubMed]

73. Wang, Y.; Zeng, G.; Jiang, Y. The Emerging Roles of miR-125b in Cancers. Cancer Manag. Res. 2020, 12, 1079-1088. [CrossRef] [PubMed]

74. Li, H.; Mou, Q.; Li, P.; Yang, Z.; Wang, Z.; Niu, J.; Liu, Y.; Sun, Z.; Lv, S.; Zhang, B.; et al. MiR-486-5p inhibits IL-22-induced epithelial-mesenchymal transition of breast cancer cell by repressing Dock1. J. Cancer 2019, 10, 4695-4706. [CrossRef] [PubMed]

75. Xiao, Y.; Humphries, B.; Yang, C.; Wang, Z. MiR-205 Dysregulations in Breast Cancer: The Complexity and Opportunities. Noncoding RNA 2019, 5, 53. [CrossRef] [PubMed]

76. Pajic, M.; Froio, D.; Daly, S.; Doculara, L.; Millar, E.; Graham, P.H.; Drury, A.; Steinmann, A.; de Bock, C.E.; Boulghourjian, A.; et al. miR-139-5p Modulates Radiotherapy Resistance in Breast Cancer by Repressing Multiple Gene Networks of DNA Repair and ROS Defense. Cancer Res. 2018, 78, 501-515. [CrossRef]

77. Xia, M.; Li, H.; Wang, J.J.; Zeng, H.J.; Wang, S.H. MiR-99a suppress proliferation, migration and invasion through regulating insulin-like growth factor 1 receptor in breast cancer. Eur. Rev. Med. Pharmacol. Sci. 2016, 20, 1755-1763.

78. Gao, L.; Guo, Q.; Li, X.; Yang, X.; Ni, H.; Wang, T.; Zhao, Q.; Liu, H.; Xing, Y.; Xi, T.; et al. MiR-873/PD-L1 axis regulates the stemness of breast cancer cells. EBioMedicine 2019, 41, 395-407. [CrossRef]

79. Chen, J.; Shin, V.Y.; Siu, M.T.; Ho, J.C.; Cheuk, I.; Kwong, A. miR-199a-5p confers tumor-suppressive role in triple-negative breast cancer. BMC Cancer 2016, 16, 887. [CrossRef]

80. Fedele, M.; Cerchia, L.; Chiappetta, G. The Epithelial-to-Mesenchymal Transition in Breast Cancer: Focus on Basal-Like Carcinomas. Cancers 2017, 9, 134. [CrossRef]

81. Rakha, E.A.; Green, A.R. Molecular classification of breast cancer: What the pathologist needs to know. Pathology 2017, 49, 111-119. [CrossRef] [PubMed]

82. Rahmani, F.; Ferns, G.A.; Talebian, S.; Nourbakhsh, M.; Avan, A.; Shahidsales, S. Role of regulatory miRNAs of the PI3K/AKT signaling pathway in the pathogenesis of breast cancer. Gene 2020, 737, 144459. [CrossRef] [PubMed]

83. Gao, X.; Qin, T.; Mao, J.; Zhang, J.; Fan, S.; Lu, Y.; Sun, Z.; Zhang, Q.; Song, B.; Li, L. PTENP1/miR-20a/PTEN axis contributes to breast cancer progression by regulating PTEN via PI3K/AKT pathway. J. Exp. Clin. Cancer Res. 2019, 38, 256. [CrossRef] [PubMed]

84. Kjaer, I.M.; Bechmann, T.; Brandslund, I.; Madsen, J.S. Prognostic and predictive value of EGFR and EGFR-ligands in blood of breast cancer patients: A systematic review. Clin. Chem. Lab. Med. 2018, 56, 688-701. [CrossRef] 
85. Huang, J.; Luo, Q.; Xiao, Y.; Li, H.; Kong, L.; Ren, G. The implication from RAS/RAF/ERK signaling pathway increased activation in epirubicin treated triple negative breast cancer. Oncotarget 2017, 8, 108249-108260. [CrossRef]

86. Tobin, N.P.; Bergh, J. Analysis of Cyclin D1 in Breast Cancer: A Call to Arms. Curr. Breast Cancer Rep. 2012, 4, 171-173. [CrossRef]

87. Kim, I.; Choi, S.; Kim, S. BRCA-Pathway: A structural integration and visualization system of TCGA breast cancer data on KEGG pathways. BMC Bioinform. 2018, 19, 42. [CrossRef]

88. Chen, J.; Jiang, Q.; Jiang, X.Q.; Li, D.Q.; Jiang, X.C.; Wu, X.B.; Cao, Y.L. miR-146a promoted breast cancer proliferation and invasion by regulating NM23-H1. J. Biochem. 2020, 167, 41-48. [CrossRef]

89. Marques, M.M.; Evangelista, A.F.; Macedo, T.; Vieira, R.A.D.C.; Scapulatempo-Neto, C.; Reis, R.M.; Carvalho, A.L.; Silva, I.D.C.G.D. Expression of tumor suppressors miR-195 and let-7a as potential biomarkers of invasive breast cancer. Clinics 2018, 73, e184. [CrossRef]

90. Yin, C.; Zhang, G.; Sun, R.; Pan, X.; Wang, X.; Li, H.; Sun, Y. miR-185-5p inhibits F-actin polymerization and reverses epithelial mesenchymal transition of human breast cancer cells by modulating RAGE. Mol. Med. Rep. 2018, 18, 2621-2630. [CrossRef]

91. Maskey, N.; Li, D.; Xu, H.; Song, H.; Wu, C.; Hua, K.; Song, J.; Fang, L. MicroRNA-340 inhibits invasion and metastasis by downregulating ROCK1 in breast cancer cells. Oncol. Lett. 2017, 14, 2261-2267. [CrossRef]

92. Zearo, S.; Kim, E.; Zhu, Y.; Zhao, J.T.; Sidhu, S.B.; Robinson, B.G.; Soon, P.S. MicroRNA-484 is more highly expressed in serum of early breast cancer patients compared to healthy volunteers. BMC Cancer 2014, 14, 200. [CrossRef] [PubMed]

93. McAnena, P.; Tanriverdi, K.; Curran, C.; Gilligan, K.; Freedman, J.E.; Brown, J.A.L.; Kerin, M.J. Circulating microRNAs miR-331 and miR-195 differentiate local luminal a from metastatic breast cancer. BMC Cancer 2019, 19, 436. [CrossRef] [PubMed]

94. Zhang, H.D.; Sun, D.W.; Mao, L.; Zhang, J.; Jiang, L.H.; Li, J.; Wu, Y.; Ji, H.; Chen, W.; Wang, J.; et al. MiR-139-5p inhibits the biological function of breast cancer cells by targeting Notch1 and mediates chemosensitivity to docetaxel. Biochem. Biophys. Res. Commun. 2015, 465, 702-713. [CrossRef] [PubMed]

95. Tuaeva, N.O.; Falzone, L.; Porozov, Y.B.; Nosyrev, A.E.; Trukhan, V.M.; Kovatsi, L.; Spandidos, D.A.; Drakoulis, N.; Kalogeraki, A.; Mamoulakis, C.; et al. Translational Application of Circulating DNA in Oncology: Review of the Last Decades Achievements. Cells 2019, 8, 1251. [CrossRef]

96. Falzone, L.; Musso, N.; Gattuso, G.; Bongiorno, D.; Palermo, C.; Scalia, G.; Libra, M.; Stefani, S. Sensitivity assessment of droplet digital PCR for SARS-CoV-2 detection. Int. J. Mol. Med. 2020, 46, 957-964. [CrossRef]

97. Filetti, V.; Falzone, L.; Rapisarda, V.; Caltabiano, R.; Eleonora Graziano, A.C.; Ledda, C.; Loreto, C. Modulation of microRNA expression levels after naturally occurring asbestiform fibers exposure as a diagnostic biomarker of mesothelial neoplastic transformation. Ecotoxicol. Environ. Saf. 2020, 198, 110640. [CrossRef]

98. Battaglia, R.; Palini, S.; Vento, M.E.; La Ferlita, A.; Lo Faro, M.J.; Caroppo, E.; Borzì, P.; Falzone, L.; Barbagallo, D.; Ragusa, M.; et al. Identification of extracellular vesicles and characterization of miRNA expression profiles in human blastocoel fluid. Sci. Rep. 2019, 9, 84. [CrossRef]

99. Salemi, R.; Falzone, L.; Madonna, G.; Polesel, J.; Cinà, D.; Mallardo, D.; Ascierto, P.A.; Libra, M.; Candido, S. MMP-9 as a Candidate Marker of Response to BRAF Inhibitors in Melanoma Patients With BRAFV600E Mutation Detected in Circulating-Free DNA. Front. Pharmacol. 2018, 9, 856. [CrossRef]

100. Falzone, L.; Scola, L.; Zanghì, A.; Biondi, A.; Di Cataldo, A.; Libra, M.; Candido, S. Integrated analysis of colorectal cancer microRNA datasets: Identification of microRNAs associated with tumor development. Aging 2018, 10, 1000-1014. [CrossRef]

101. Tang, Z.; Li, C.; Kang, B.; Gao, G.; Li, C.; Zhang, Z. GEPIA: A web server for cancer and normal gene expression profiling and interactive analyses. Nucleic Acids Res. 2017, 45, W98-W102. [CrossRef] [PubMed]

102. Cui, C.; Cui, Q. The relationship of human tissue microRNAs with those from body fluids. Sci. Rep. 2020, 10, 5644. [CrossRef] [PubMed]

103. Tokar, T.; Pastrello, C.; Rossos, A.E.M.; Abovsky, M.; Hauschild, A.C.; Tsay, M.; Lu, R.; Jurisica, I. mirDIP 4.1-integrative database of human microRNA target predictions. Nucleic Acids Res. 2018, 46, D360-D370. [CrossRef] [PubMed]

104. Falzone, L.; Romano, G.L.; Salemi, R.; Bucolo, C.; Tomasello, B.; Lupo, G.; Anfuso, C.D.; Spandidos, D.A.; Libra, M.; Candido, S. Prognostic significance of deregulated microRNAs in uveal melanomas. Mol. Med. Rep. 2019, 19, 2599-2610. [CrossRef] 
105. Vlachos, I.S.; Zagganas, K.; Paraskevopoulou, M.D.; Georgakilas, G.; Karagkouni, D.; Vergoulis, T.; Dalamagas, T.; Hatzigeorgiou, A.G. DIANA-miRPath v3.0: Deciphering microRNA function with experimental support. Nucleic Acids Res. 2015, 43, W460-W466. [CrossRef]

106. Szklarczyk, D.; Gable, A.L.; Lyon, D.; Junge, A.; Wyder, S.; Huerta-Cepas, J.; Simonovic, M.; Doncheva, N.T.; Morris, J.H.; Bork, P.; et al. STRING v11: Protein-protein association networks with increased coverage, supporting functional discovery in genome-wide experimental datasets. Nucleic Acids Res. 2019, 47, D607-D613. [CrossRef]

107. Mi, H.; Muruganujan, A.; Ebert, D.; Huang, X.; Thomas, P.D. PANTHER version 14: More genomes, a new PANTHER GO-slim and improvements in enrichment analysis tools. Nucleic Acids Res. 2019, 47, D419-D426. [CrossRef]

108. Anaya, J. OncoLnc: Linking TCGA survival data to mRNAs, miRNAs, and lncRNAs. PeerJ Comput. Sci. 2016, 2, e67. [CrossRef]

(C) 2020 by the authors. Licensee MDPI, Basel, Switzerland. This article is an open access article distributed under the terms and conditions of the Creative Commons Attribution (CC BY) license (http://creativecommons.org/licenses/by/4.0/). 